\title{
Assessing Fire-blocking Effectiveness of Barrier Fabrics in the Cone Calorimeter
}

\author{
Shonali Nazaré \\ William M. Pitts \\ John R. Shields \\ Elizabeth Knowlton \\ Benito De Leon \\ Mauro Zammarano \\ Rick D. Davis
}

This publication is available free of charge from:

https://doi.org/10.6028/NIST.TN.2043 


\title{
Assessing Fire-blocking Effectiveness of Barrier Fabrics in the Cone Calorimeter
}

\author{
Shonali Nazaré \\ William M. Pitts \\ John R. Shields \\ Elizabeth Knowlton \\ Benito De Leon \\ Mauro Zammarano \\ Rick D. Davis \\ Fire Research Division \\ Engineering Laboratory
}

This publication is available free of charge from:

https://doi.org/10.6028/NIST.TN.2043

April 2019

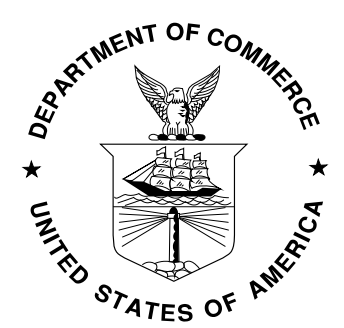

U.S. Department of Commerce Wilbur L. Ross, Jr., Secretary

National Institute of Standards and Technology Walter Copan, NIST Director and Undersecretary of Commerce for Standards and Technology 
Certain commercial entities, equipment, or materials may be identified in this document in order to describe an experimental procedure or concept adequately. Such identification is not intended to imply recommendation or endorsement by the National Institute of Standards and Technology, nor is it intended to imply that the entities, materials, or equipment are necessarily the best available for the purpose.

National Institute of Standards and Technology Technical Note 2043

Natl. Inst. Stand. Technol. Tech. Note 2043, 53 pages (April 2019)

CODEN: NTNOEF

This publication is available free of charge from:

https://doi.org/10.6028/NIST.TN.2043 


\begin{abstract}
Cone calorimetric experiments of flexible polyurethane foam (FPUF) and FPUF covered with a variety of fire-blocking barrier fabrics (BFs) were used to characterize and rank the effectiveness of BFs for reducing the flammability of residential upholstered furniture (RUF). In addition to BF properties, it was demonstrated that the burning behaviors of the FPUF/BF composites were sensitive to a wide range of experimental parameters including the sample configuration, heat losses to the underlying support base, and the two-stage pyrolysis behavior of the FPUF. Measurements using thermocouples (TCs) placed within the FPUF provided insights on FPUF pyrolysis behavior, the collapse rate of FPUF, and the thermal protective properties of barrier materials.
\end{abstract}

Seven out of 16 FPUF/BF composites exhibited flame extinction during testing. Five out of the seven composites reignited when the spark ignition source was reapplied. Reignition allowed BF effectiveness to be assessed even for cases with flame extinction. Heat release rate (HRR) temporal profiles were measured for bare FPUF and the FPUF/BF composites. For cases where large rapid changes in HRR, e.g., during flash burning of a BF, occurred, it was necessary to correct the profiles for the finite time response of the cone calorimeter. The HRR curves for FPUF consisted of two distinct burning periods which were previously associated with sequential burning of foam pyrolyzates derived from the isocyanate and deposited liquid polyol components used in its manufacture. Tests with two different underlying substrates demonstrated the sensitivity of the second-stage liquid burning to heat losses from the sample holder. The majority of the HRR curves for the FPUF/BF composites showed evidence for three-stage burning, which was attributed to initial flash burning of the BF followed by the two-stage burning of the underlying FPUF.

For most of the composites, the largest HRR peak, which is often used as the primary indicator for a material's flammability, occurred during the short-lived burning of the BF. Since this is not an appropriate measure of BF effectiveness, it is proposed here that effectiveness should be based on a BF's ability to reduce the HRR from the underlying FPUF. In general, the presence of a BF was shown to reduce the HRR peak values during both FPUF burning stages. The magnitude of the peak associated with second-stage FPUF burning (denoted PHRR 2 ) was deemed the most appropriate for characterizing the thermal protection provided by a BF. Since the times for $\mathrm{PHRR}_{2}$ also varied between composites, a measurement referred to as the peak fire growth rate (PFIGRA) parameter was calculated by dividing the PHRR by time since time to ignition was also considered for characterizing the BFs.

Three possible classification schemes, each consisting of three classes, were introduced based on composite flame extinction and reignition behavior, $\mathrm{PHRR}_{2}$ values, and PFIGRA 2 values. Each scheme provided differentiation between BF effectiveness. While the schemes were able to assess whether the BFs were particularly effective or ineffective, there were variations among classes of BFs having intermediate levels of effectiveness. Further work will be required to assess which, if any, of the classification schemes are most appropriate for predicting BF performance in RUF.

BF performance was shown to be associated with four properties that were previously identified as important BF properties: BF flammability, gas permeability, thermal protection, 
and physical integrity. In addition, the current experiments indicate the presence and effectiveness of gas-phase active flame retardants in the BF can also play an important role. A limited number of tests were conducted to de-couple the effects of flame-retardant chemicals and physical effects of BFs on FPUF burning behavior. These tests showed that while flameretardant chemicals can be effective in quenching and extinguishing the flames, the presence of effective BF shells is also very important in lowering the HRR of burning FPUF.

\section{Key words}

Barrier fabrics; cone calorimetry; furniture flammability; flexible polyurethane foam; heat release rates; residential upholstered furniture temperature measurements. 


\section{Table of Contents}

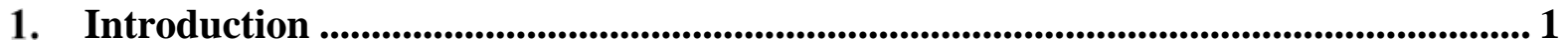

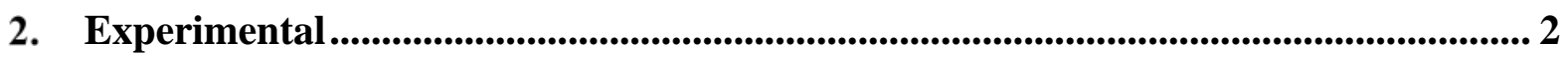

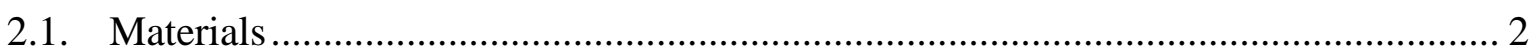

2.2. Cone Calorimetry …...................................................................................... 5

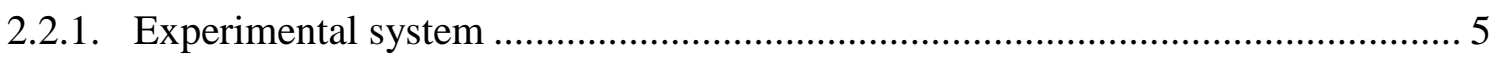

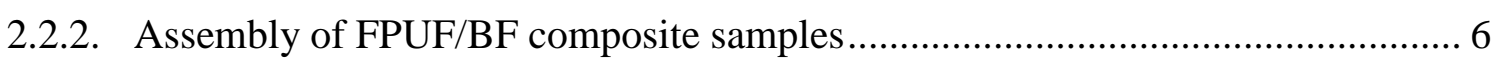

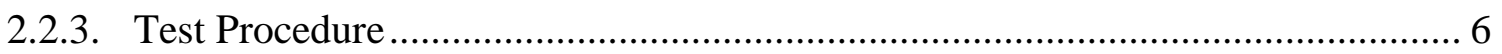

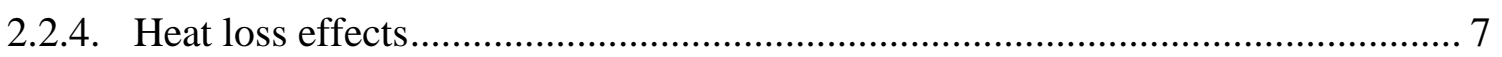

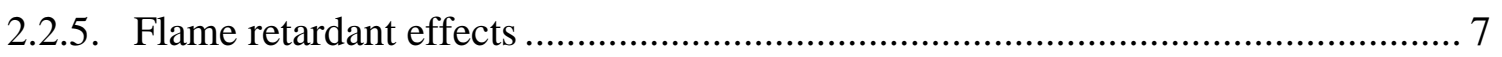

2.2.6. Correction for time response ........................................................................ 7

2.2.7. Parameters to characterize HRR temporal profiles .......................................... 8

2.2.8. Thermocouple measurements ................................................................. 9

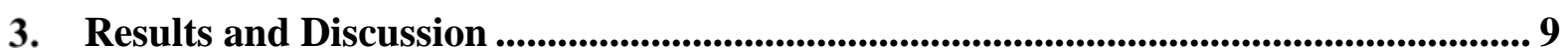

3.1. Reproducibility of HRR Temporal Profiles ........................................................... 9

3.2. Corrected Time Response HRR Data.............................................................. 10

3.3. Burning Behavior of Flexible Polyurethane Foam.............................................. 13

3.4. Thermocouple Measurements in FPUF/BF Composites ....................................... 15

3.5. Burning Behavior of FPUF/BF Composites .................................................... 18

3.6. Decoupling roles of active and passive effects on flame extinction ...................... 29

3.7. Ranking of Barrier Fabric Effectiveness ......................................................... 31

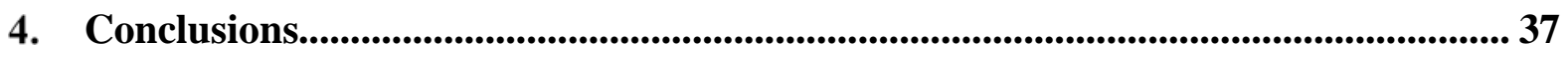

References...................................................................................................... 40

\section{List of Tables}

Table 1. Description of barrier fabrics (BFs) and their physical properties [6-8].

Uncertainties are reported as experimental standard deviations.

Table 2. Comparison of the measured and corrected PHRR values for initial peaks in HRR curves (PHRR $\mathrm{BF}_{\mathrm{BF}}$ ) and corresponding times to peak $\left(\mathrm{TTP}_{\mathrm{BF}}\right)$ for FPUF/BF composites. Uncertainties are reported as experimental standard deviations.

Table 3. Times at which the pyrolysis front passes over top, middle and bottom TCs and collapse rates of FPUF within FPUF/BF $\mathrm{BF}^{\S}$ composites exposed to $35 \mathrm{~kW} / \mathrm{m}^{2}$ heat flux in the cone calorimeter. Variations among repeated FPUF samples are reported as experimental standard deviations. Barriers are grouped as highloft, flat-permeable, and flat impermeable. 
Table 4. Burning behavior of FPUF and FPUF/BF composites in the cone calorimetry tests and description of sample residue. Uncertainties are reported as experimental standard deviations. Numbers in parentheses represent occurrence of events per repeated tests. ...... 19

Table 5. Cone calorimetry data for FPUF and FPUF/BF composites at $35 \mathrm{~kW} / \mathrm{m}^{2}$ heat flux.

Uncertainties are reported as experimental standard deviations. 28

Table 6. Classification of BF effectiveness based on flame extinction behavior. ................. 31

Table 7. Classification of BF effectiveness based on $\mathrm{PHRR}_{2}$ values.................................. 35

Table 8. Classification of BFs based on PFIGRA 2 values. ................................................. 36

\section{List of Figures}

Fig. 1. Schematic drawing showing the sample configuration and TC placement for temperature measurements during cone calorimetry experiments. Note: drawing not to scale......

Fig. 2. Reproducibility data examples for (a) FPUF and FPUF/BF composites with (b) highloft BF, (c) flat permeable BF, and (d) flat impermeable BF.

Fig. 3. Measured and corrected HRR temporal profiles for (a) FPUF and (b) FPUF/BF-5 and (c) FPUF/BF-19 composites. 11

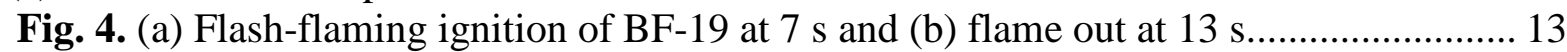

Fig. 5. Heat release data for FPUF with different sample holder substrates. 14

Fig. 6. Top, middle and bottom TC measurements within the (a) FPUF, (b) FPUF/BF-5, (c) FPUF/BF-8, and (d) FPUF/BF-19.

Fig. 7. Comparison of characteristic time-temperature profiles recorded by the top TC for bare FPUF and FPUF/BF composites with (a) highloft, permeable BFs, (b) flat, permeable, and self-extinguishing BFs, (c) flat, permeable BFs and (d) flat, impermeable BFs. 18 Fig. 8. Heat release rate and mass loss data for FPUF/BF composites with highloft barriers: (a) BF-1, (b) BF-2, (c) BF-4, (d) BF-5, and (e) BF-24. The time when the pyrolysis front passed the third TC and the remaining sample mass are indicated in $\mathrm{s}$ and \% respectively. . 20 Fig. 9. Heat release rates and mass loss data for FPUF/BF composites with flat, permeable barriers showing flame extinction: (a) BF-9, (b) BF-13, (c) BF-15, and (d) BF-16. The time when the pyrolysis front passed the third TC and the remaining sample mass are indicated in $\mathrm{s}$ and \% respectively.....

Fig. 10. Heat release rates and mass loss data for FPUF/BF composites with flat, permeable barriers showing no flame extinction: (a) BF-8, (b) BF-10, (c) BF-14, and (d) BF-21. The time when the pyrolysis front passed the third TC and the remaining sample mass are indicated in s and \% respectively.

Fig. 11. Heat release and mass loss data for FPUF/BF composites with flat impermeable barriers: a) FPUF/BF-19, (b) FPUF/BF-20, and (c) FPUF/BF-23. The time when the pyrolysis front passed the third TC and the remaining sample mass are indicated in $\mathrm{s}$ and \% respectively.

Fig. 12. Digital image of (a) FPUF/BF-10 and (b) FPUF/BF-21 composite showing opening of BF-10 char during burning and cracks in brittle char of BF-21 respectively................... 24 Fig. 13. Digital image showing a mixture of liquid material and char present at the end of a test for a FPUF/BF-16 composite.

Fig. 14. Digital images of unburnt (a) FPUF for a test terminated immediately after the flaming phase and (b) liquid/char at the end of a full test of FPUF/BF-19 composites. 25 
Fig. 15. Comparison of HRR profiles (corrected for time response effects) with unburnt pristine and burnt BF shell for (a) FPUF/BF-13, (b) FPUF/BF-15, and (c) FPYF/BF-16 composites.

Fig. 16. Changes in (a) $\mathrm{PHRR}_{1}$ and $\mathrm{PHRR}_{2}$, (b) THR, and (c) Avg. HRR for FPUF composites as compared to FPUF alone tested under $35 \mathrm{~kW} / \mathrm{m}^{2}$ heat flux in the cone calorimeter. 33

Fig. 17. Ranking of barrier fabrics (BFs) using $\mathrm{PHRR}_{2}$ of the FPUF/BF composites.......... 34

Fig. 18. Ranking of barrier fabrics (BFs) using PFIGRA 2 of the FPUF/BF composites. ..... 36 


\section{List of Symbols and Abbreviation}

Symbols

\begin{tabular}{|c|c|}
\hline$H R R_{c o r r}$ & Corrected heat release rate $\left(\mathrm{kW} / \mathrm{m}^{2}\right)$ \\
\hline$H R R_{\text {meas }}$ & Measured heat release rate $\left(\mathrm{kW} / \mathrm{m}^{2}\right)$ \\
\hline$k$ & calorimeter time constant \\
\hline $\mathrm{PHRR}_{1}$ & $\begin{array}{l}\text { Peak heat release rate due to burning of the pyrolyzate of species derived } \\
\text { from the toluene diisocyante component of the flexible polyurethane foam } \\
\left(\mathrm{kW} / \mathrm{m}^{2}\right)\end{array}$ \\
\hline $\mathrm{PHRR}_{2}$ & $\begin{array}{l}\text { Peak heat release rate due to burning of the pyrolyzate of species derived } \\
\text { from the polyol component }\left(\mathrm{kW} / \mathrm{m}^{2}\right)\end{array}$ \\
\hline PHRR $_{B F}$ & Peak heat release rate due to burning of the barrier fabric $\left(\mathrm{kW} / \mathrm{m}^{2}\right)$ \\
\hline PFIGRA $_{1}$ & $\begin{array}{l}\text { Peak FIGRA value due to burning of the pyrolyzate of species derived from } \\
\text { the toluene diisocyante component of the flexible polyurethane foam } \\
\left(\mathrm{kW} / \mathrm{m}^{2} \bullet \mathrm{s}\right)\end{array}$ \\
\hline PFIGRA $_{2}$ & $\begin{array}{l}\text { Peak FIGRA value due to burning of the pyrolyzate of species derived from } \\
\text { the polyol component }\left(\mathrm{kW} / \mathrm{m}^{2} \bullet \mathrm{s}\right)\end{array}$ \\
\hline PFIGRA $_{B F}$ & Peak FIGRA value due to burning of the barrier fabric $\left(\mathrm{kW} / \mathrm{m}^{2} \bullet \mathrm{s}\right)$ \\
\hline$t$ & Time (s) \\
\hline $\mathrm{TTP}_{\mathrm{BF}}$ & Time to PHRR due to burning of the barrier fabric (s) \\
\hline
\end{tabular}

Abbreviations

ASTM ASTM International Standard

BF Barrier fabric

FPUF Flexible polyurethane foam

RUF Residential upholstered furniture

HRR Heat release rate

PHRR Peak heat release rate

PFIGRA Peak Fire growth rate

FR Flame retardant

CPSC Consumer Product Safety Commission

Cal TB California Test Bulletin 


\begin{tabular}{|c|c|}
\hline NA & Not available \\
\hline NIST & National Institute of Standards and Technology \\
\hline CBUF & Combustion Behavior of Upholstered Furniture \\
\hline $\mathrm{TC}$ & Thermocouple \\
\hline TDI & Toluene diisocyante \\
\hline THR & Total heat release \\
\hline TTI & Time to ignition \\
\hline TTP & Time to peak \\
\hline
\end{tabular}




\section{Introduction}

Fires in residences remain a significant source of injuries, deaths, and financial loss in the United States. Recent analyses indicate that ignition of and fire growth on residential upholstered furniture (RUF) continues to be associated with a large fraction of these losses [1,2]. In recent years, fires involving RUF have resulted in over 600 annual fire deaths, representing roughly $25 \%$ of the total in residences [2]. Fires in rooms that typically contain RUF are more than ten times likely to be fatal than fires elsewhere in a residence [1, 2]. These high losses are associated with rapid rates of fire growth on RUF to heat release rate (HRR) levels sufficient to induce flashover. Studies starting in the 1970s have demonstrated that many items of RUF display such burning behaviors due to the use of modern man-made materials in their construction [3].

It has long been recognized that the use of fire-blocking barrier fabrics (BFs) to protect underlying cushioning materials has the potential to improve the flammability performance of RUF by significantly reducing fire growth rate and maximum HRR [4]. The purpose of a BF is to limit the cushioning material's involvement in a fire by preventing and/or significantly delaying the ignition of core materials, reducing the rate of flame spread, lowering the HRR, and/or extinguishing the flames $[5,6]$. Previous studies $[6,7,8]$ in our laboratories have shown that many factors contribute to the capabilities of a given BF to protect the underlying FPUF. Material properties such as flame retardancy, gas permeability, heat transfer rate, and physical integrity under heating have strong influences on the protective performance of BFs.

To our knowledge, fire-blocking BFs have not been widely used in RUF construction, even though they have been employed in residential mattresses and contract furnishing where government regulations have required improvements in flammability behavior. One potential obstacle to the use of BFs in RUF is the lack of a suitable small-scale test method for predicting their potential effectiveness for improving RUF burning behavior. In this study, we examine a small-scale test using cone calorimetry which we believe may offer an approach for assessing BF effectiveness in RUF applications.

The effective design of less flammable RUF incorporating barrier fabrics would be greatly aided by approaches for predicting the effectiveness of a given barrier fabrics. Over the years, cone calorimetry has been widely used as a small-scale test for characterizing the flammability of FPUF, FPUF composites, and BFs, and attempts (of varying success) have been made to correlate the small-scale results with the burning behavior of real-scale RUF. Several researchers have reported on cone calorimetric testing of flexible polyurethane foam FPUF/fabric composites [9-23]. Most studies [9, 12-15, 20-26] used HRR data for screening upholstery materials, while others [16, 17, 27] employed the approach to study the effects of flame retardants on the burning behavior of FPUF/fabric composites. A few studies [25, 26, $28,29]$ have focused on cone calorimetry to test BF performance in FPUF/fabric composites. However, these studies included cover fabrics in their composites and often concluded that the peak heat release rate (PHRR) was dominated by the cover fabrics.

Other cone calorimetric studies suggest PHRR value may not be a good indicator of BF effectiveness. Recent cone test [26, 28-30] on the flammability of FPUF/fabric composites, which included BFs, concluded that the PHRR parameter does not adequately characterize 
barrier fabric effectiveness. Schartel et al [31] showed that the PHRR measured in cone calorimetry experiments is not an intrinsic material property, but is strongly dependent on the setup, sample thickness, and sample configuration. This is particularly true in the case of FPUF/fabric composites where two or more distinct peaks are typically observed. The first peak is dominated by cover fabric burning and the subsequent peak(s) by FPUF burning. The above suggests that the use of PHRR value may not be an appropriate metric for evaluating BF effectiveness.

In this study, experiments were conducted such that individual BF effectiveness could be studied without cover fabric influences. This allowed direct comparison of FPUF combustion with and without BF, therefore providing a measure of BF effectiveness. The effectiveness of different BFs and the mechanisms by which they protect the flammable cushioning component are discussed.

In order to provide additional insights into BF effectiveness, thermocouples (TCs) were embedded in the FPUF. Similar approaches have previously been used to assess the performance of intumescent coatings [32-35] and to understand pyrolysis conditions and flame retardant mechanisms in bulk polymers [36]. Recently, Schartel and Weiß [36] used TCs to gain experimental insights into the pyrolysis conditions and flame retardancy mechanism in poly (methyl methacrylate), epoxy resin, and epoxy resin nanocomposites. TC measurements have also been commonly used to study smoldering behaviors in FPUF [37-39]. However, TCs have not been used to investigate barrier effectiveness in FPUF/BF composites. In this work, the response of TCs embedded within the FPUF of FPUF/BF composites during the cone calorimeter experiments is used to estimate the velocity of the pyrolysis front and the collapse rate of the FPUF.

\section{Experimental}

\subsection{Materials}

Sixteen commercially available BFs were included in this study. BF characteristics, such as construction type, area density, thickness, and air permeability, are provided in Table 1 [6, 7]. Multiple repeats (at least 3) were performed, and averages and standard deviations are provided. Experimental details are provided in the earlier publications [6-8]. Note that the polyester batting, BF-24, is included because it is frequently cited as a barrier for smoldering ignition, even though it is not expected to act as an effective barrier in these experiments. The identification numbers assigned in the table are identical to those used in our previous studies of the same BFs [6-8]. The omission of BFs included in the earlier studies was largely due to the similarity of fabric structures (BF-11 and BF-12 both knitted and similar to BF-13 and BF17 and BF-18 both woven glass and similar to BF-19). The experimental matrix covers the most extensively used fibers and fiber blends in the BF industry. The list includes a variety of textile structures including highloft battings, nonwoven felts, knitted and woven fabrics, and coated fabrics. Materials represented include flame retardant $\left(\mathrm{FR}^{\S}\right)$ rayon, low-melt polyester, $\mathrm{FR}^{\S}$ polyester, glass fiber, aramid fibers, and blends thereof. BFs made with core-yarn

\footnotetext{
${ }^{\S}$ Proprietary FR formulation.
} 
technology and high-performing polyaramid/melamine fiber blends are also included. In many cases the exact fiber blend compositions are proprietary and thus were not known.

The BFs in Table 1 are assigned to three groups based on structure and air permeability. BFs are characterized as highly thermally insulating highloft materials, flat permeable structures, and flat impermeable structures. Flat BFs include densified nonwoven felts, woven, knitted, and coated fabrics. For the purposes of this study, impermeable barriers are defined as barriers with air permeabilities (measured with the target pressure drop of $125 \mathrm{~Pa}$ [7]) less than $1 \mathrm{~m} / \mathrm{s}$. These barriers are expected to reduce the HRR by limiting gas transport of FPUF pyrolyzates through the barrier. 
Table 1. Description of barrier fabrics (BFs) and their physical properties [6-8]. Uncertainties are reported as experimental standard deviations.

\begin{tabular}{|c|c|c|c|c|c|c|c|}
\hline Types of BFs & Sample & Fiber Blend & Structure & FR system & $\begin{array}{c}\text { Thickness } \\
\text { (mm) }\end{array}$ & $\begin{array}{l}\text { Area density } \\
\qquad\left(\mathrm{g} / \mathrm{m}^{2}\right)\end{array}$ & $\begin{array}{c}\text { Air } \\
\text { permeability* } \\
(\mathrm{m} / \mathrm{s})\end{array}$ \\
\hline \multirow{5}{*}{$\begin{array}{l}\text { Highloft, } \\
\text { permeable }\end{array}$} & BF-1 & $\begin{array}{l}\text { Flame retarded (FR) } \\
\text { rayon/polyester }\end{array}$ & $\begin{array}{l}\text { Nonwoven } \\
\text { Stratified }\end{array}$ & Passive & $4.1 \pm 0.1$ & 155 & $2.8 \pm 0.2$ \\
\hline & BF-2 & $\begin{array}{l}\text { Flame retarded (FR) } \\
\text { rayon/polyester }\end{array}$ & $\begin{array}{l}\text { Nonwoven } \\
\text { Stratified }\end{array}$ & Passive & $6.7 \pm 0.2$ & 230 & $2.0 \pm 0.1$ \\
\hline & BF-4 & $\begin{array}{l}\text { Boric acid treated cotton/ } \\
\text { FR rayon/polyester }\end{array}$ & $\begin{array}{l}\text { Needle punched } \\
\text { Stratified }\end{array}$ & Passive & $5.7 \pm 0.1$ & 230 & $2.2 \pm 0.2$ \\
\hline & $\mathrm{BF}-5$ & Boric acid treated cotton & Needle punched & Passive & $6.9 \pm 0.8$ & 230 & $1.3 \pm 0.1$ \\
\hline & BF-24 & Polyester & Nonwoven batting & - & $8.13 \pm 1.1$ & 165 & $7.6 \pm 0.2$ \\
\hline \multirow{8}{*}{$\begin{array}{c}\text { Flat } \\
\text { Permeable }\end{array}$} & BF-8 & FR rayon/polyester & Nonwoven felt & Passive & $4.3 \pm 0.1$ & 237 & $2.2 \pm 0.1$ \\
\hline & BF-9 & $\begin{array}{l}\text { FR rayon/polyester/para- } \\
\text { aramid }\end{array}$ & Nonwoven felt & Passive & $2.2 \pm 0.1$ & 240 & $1.5 \pm 0.1$ \\
\hline & BF-10 & FR polyester/FR rayon & Stitchbond & Active/passive & $0.7 \pm 0.1$ & 165 & $1.1 \pm 0.1$ \\
\hline & BF-13 & $\begin{array}{l}\text { Glass fiber core/FR } \\
\text { acrylic fiber (core spun } \\
\text { yarn) }\end{array}$ & Knitted & Active/passive & $1.4 \pm 0.1$ & 165 & $1.9 \pm 0.1$ \\
\hline & BF-14 & Carbon fiber & Knitted & Passive & $1.2 \pm 0.1$ & 250 & $1.2 \pm 0.1$ \\
\hline & BF-15 & $\begin{array}{l}\text { Glass fiber core/FR } \\
\text { acrylic fiber }\end{array}$ & Woven & Active/passive & $0.5 \pm 0.1$ & 170 & $2.1 \pm 0.1$ \\
\hline & BF-16 & $\begin{array}{l}\text { FR rayon/glass fiber/Poly } \\
\text { Lactic Acid (PLA) fiber }\end{array}$ & Nonwoven & Active/passive & $2.9 \pm 0.1$ & 290 & $1.9 \pm 0.2$ \\
\hline & BF-21 & Para-aramid & Nonwoven & Passive & $0.67 \pm 0.02$ & 69 & $2.1 \pm 0.1$ \\
\hline \multirow{3}{*}{$\begin{array}{c}\text { Flat } \\
\text { Impermeable }\end{array}$} & BF-19 & Glass filaments & Woven & Active/passive & $0.3 \pm 0.1$ & 320 & 0 \\
\hline & BF-20 & Para-aramid/melamine & Woven & Passive & $0.77 \pm 0.02$ & 264 & $0.2 \pm 0.1$ \\
\hline & BF-23 & Cotton/glass fiber & Back-coated & Active/passive & $1.5 \pm 0.1$ & 284 & 0 \\
\hline
\end{tabular}

Note: ${ }^{\S}$ For textile materials, area density is typically expressed as mass per unit area. The standard uncertainty in measuring thickness is \pm 0.1 mm and for area density is $\pm 5 \mathrm{~g} / \mathrm{m}^{2}$. * The uncertainty in measuring air permeability is reported as the standard deviation $(\sigma)$ based on repeat measurements. 
The BFs in Table 1 are identified by the mode of fire blocking technology employed: passive, gas-phase active, or both. Passive barriers provide a physical barrier that limits mass and heat transfer between the heat source and the cushioning material. Passive BFs typically contain inherently fire-resistant fibers, such as glass and aramid. They may also contain FR chemicals that operate in the condensed phase to enhance charring, which result in a physical barrier between the fuel and the potential ignition/heat source. Active BFs contain FR chemicals that are released into and operate in the gas phase by a free-radical trapping mechanism and/or by diluting the combustible gases. Typically, halogen compounds in combination with antimony are known to be very effective active gas-phase flame retardants when added to fabrics [40]. A chemically-active barrier usually also provides some passive protection for underlying fuels.

Quantitative elemental analysis of BFs reported by UL laboratories [29] has shown that BFs identical to BF- 13 and BF-15 (FB-5 and FB-6 in [29]) contain antimony trioxide (2237 ppm and $3215 \mathrm{ppm}$ ) and high concentrations of chlorine (16.98 \% and 6.37\%). Chemical analysis of barrier fabrics reported in a similar study by the Consumer Product Safety Commission (CPSC) [41] showed that BF-16 (FB2 in [29]) contained antimony (2.6\%).

BF-10 is a proprietary blend of FR polyester and FR rayon. The FR component in the polyester fiber is known to operate in the gas-phase [40]. Composites formed with FPUF, this barrier, and a cotton cover fabric showed flame extinction behaviour when tested as a composite using a small flame as an ignition source [6]. Flame extinction was observed in the same test for composites including BF-12 (similar to BF-13), BF-15, and BF-16. Such flame extinction is consistent with an active gas-phase FR mechanism. On the contrary, flames continued to spread over the surfaces of composites with passive barriers and cotton fabric covering the FPUF. The passive barriers, however, provided protection for the underlying FPUF from heat and flames and limited FPUF pyrolysis.

Pre-cut $(100 \mathrm{~mm} \times 100 \mathrm{~mm} \times 50 \mathrm{~mm})$, non-FR FPUF blocks meeting Cal TB 117-2013 [42] requirements were procured from Innocor Foam Technologies. As reported in the certificate of analysis provided by the manufacturer, the FPUF had the following properties: density of $29.63 \mathrm{~kg} / \mathrm{m}^{3}$ and air permeability of $23.3 \mathrm{~m} / \mathrm{s}$. Uncertainty values for these measurements were not provided. However, standard uncertainties in measuring density and air permeability of FPUF have been reported to be in the range of $\pm 0.2 \mathrm{~kg} / \mathrm{m}^{3}$ to $\pm 0.9 \mathrm{~kg} / \mathrm{m}^{3}$ and $\pm 0.06 \mathrm{~m} / \mathrm{s}$ to \pm $0.25 \mathrm{~m} / \mathrm{s}$ respectively [43].

\subsection{Cone Calorimetry}

\subsubsection{Experimental system}

The Cone hardware was developed at the National Bureau of Standards, now the National Institute of Standards and Technology (NIST). The cone heater is used to apply a known and nearly constant heat flux to the sample under test [44]. Thornton's Rule [45] states that the heat released per kilogram of oxygen consumed is roughly constant for a range of organic fuels. In practice, estimating the oxygen consumption rate requires measurement of the gas mass flow rate and oxygen concentration collected in a hood above the sample. Generally, the mass flow rate measurement, in turn, requires a pressure reading from a flow measurement device and gas temperature. Additional assumptions allow the HRR to be calculated. Various equations have been developed for this purpose. Current calorimeters use digital data 
acquisition of the various measurements and Equation 13 in Reference [46] to determine the HRR. Uncertainties in HRR are typically within $5 \%$ and $10 \%$ for HRRs larger than $50 \mathrm{~kW} / \mathrm{m}^{2}$ $[47,48]$. Measurements were recorded at a $1 \mathrm{~Hz}$ rate.

The sample holder was mounted on a load cell which allowed sample mass to be recorded in real time. To prevent premature heating of the sample, a metal shutter was placed between the cone heater and sample prior to the placement of the sample. The shutter was rapidly removed, allowing for a nearly instantaneous exposure of the sample to the cone heat flux at a welldefined time.

\subsubsection{Assembly of FPUF/BF composite samples}

A protocol for assembly of FPUF/fabric composites described in the Combustion Behavior of Upholstered Furniture (CBUF) report [15] and further examined by Babrauskas and Wetterlund [23] was used to provide a guideline for repeatable fabrication procedure of our cone calorimeter samples incorporating BFs and cushioning material. The cover fabric shell described in the CBUF sample configuration was not included for the FPUF/BF composites. The BF was formed as a shell that covered the FPUF block on the top and four sides, leaving the bottom surface uncovered. The block of FPUF covered with the BF shell was placed in an aluminum foil pan (specified by ASTM 1474) of $50 \mathrm{~mm}$ depth to contain any liquid generated by FPUF pyrolysis during the test and to limit heating of the sample sides. The aluminum foil pan along with the FPUF/BF composite sample were then placed on a steel sample holder lined with ceramic wool. Fig. 1 shows a schematic drawing of the sample configuration and the sample holder.

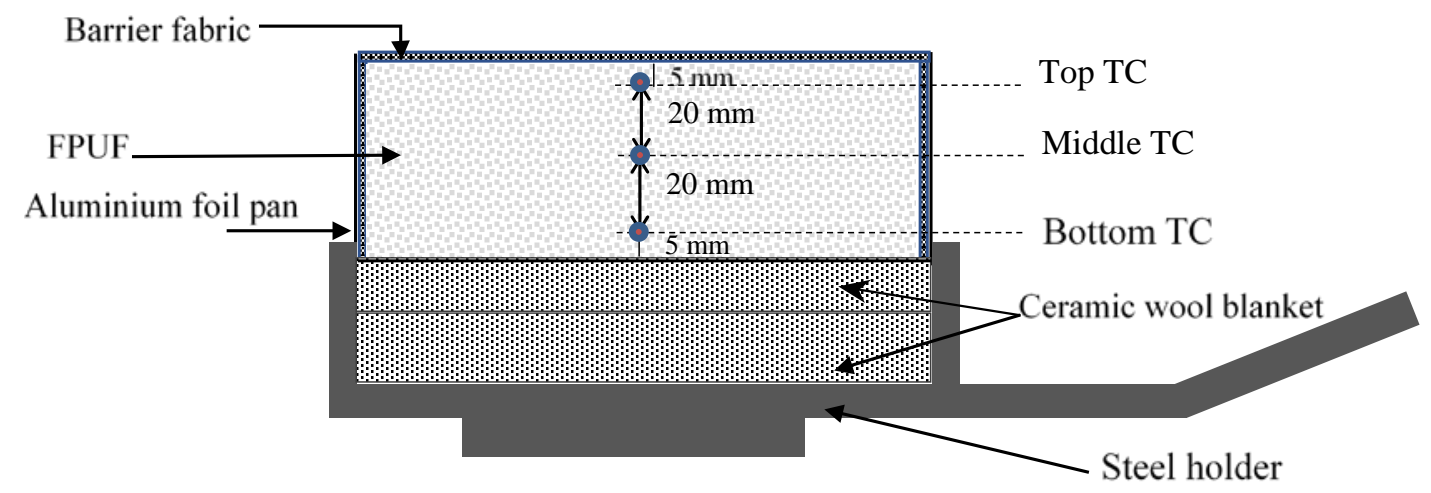

Fig. 1. Schematic drawing showing the sample configuration and TC placement for temperature measurements during cone calorimetry experiments. Note: drawing not to scale.

\subsubsection{Test Procedure}

The samples were tested in triplicate at an incident heat flux of $35 \mathrm{~kW} / \mathrm{m}^{2}$ as specified in ASTME 1474 [49] and the CBUF protocol for cone calorimeter testing of furniture composites [15]. A spark igniter was used to ignite pyrolysis gases generated by heating the sample. If a sample exhibited flame extinction, the spark igniter was re-inserted and activated 
until reignition occurred or until 10 mins had elapsed since flame extinction. The purpose of attempting reignition was to evaluate the full protective potential of the fire-blocking barrier fabrics as conditions within the sample changed.

The burning behavior of a specimen was video recorded during testing. Digital still images were taken from various locations to provide additional visual characterization.

\subsubsection{Heat loss effects}

The aluminum pan is not insulated, allowing for the potential of significant heat transfer through the sides and bottom. Changes in the heat loss from a sample to its underlying substrate are known to modify sample burning behavior. The effect of underlying substrate on the burning behavior of FPUF was assessed by performing preliminary experiments with samples placed on either the thermally insulating ceramic wool or a calcium silicate carbon fiber-reinforced substrate. The composite experiments were performed with the ceramic wool substrate.

\subsubsection{Flame retardant effects}

BFs listed in Table 1 are largely characterized as active/passive and passive barriers. As discussed earlier in Section 2.1, passive BFs provide a physical barrier between the heat source and the fuel, whereas active BFs contain chemicals that are known to extinguish flames when released into the gas phase as well as acting as passive barriers. In order to provide additional insights into the role of gas-phase active flame retardants in the burning behavior of FPUF/BF composites, BF-13, BF-15 and BF-16 shells were recovered after initial FPUF/BF testing. The used BF shells were cleared of any FPUF char and were used as barriers in new composites. The FPUF/BF composite with the used BF shell was then retested. By hypothesizing that any oxidizable organic species and flame retardants were consumed in the initial test, it was assumed that the used BF shell only contained residual, thermally stable organic compounds and inorganic fibers/filaments. The purpose of these experiments was to de-couple the effects of flame retardant chemicals and the physical effects of BFs on the burning behavior of the underlying FPUF.

\subsubsection{Correction for time response}

The various instruments used in cone calorimetry have finite time responses. As a result, the HRR measurements also have finite time responses which depend in a complicated manner on the combination of the individual responses. These finite time responses have usually been ignored in past studies. In many cases this is appropriate since the time response is relatively fast compared to temporal changes in HRR. However, for experiments where large changes in HRR occur on timescales comparable to the instrument time response, significant distortions of a measured temporal profile from the actual time behavior are possible. In cases such as the current experiments where highly flammable thin materials are involved, very rapid changes in HRR are possible, and time response effects need to be accounted for. 
The possibility of such HRR measurement distortion due to time response effects has been recognized for some time, and approaches for correcting the measured HRR curves have been developed [50, 51, 52]. Here we use a simplified approach to estimate the corrections. The analysis starts with an estimate of the calorimeter response time constant assuming it is first order, i.e., obeys an equation of the form

$H R R_{1 \rightarrow 2}(t)=\left(H R R_{2}-H R R_{1}\right)\left(1-e^{-k t}\right)+H R R_{1}$

for an instantaneous change in HRR from level 1 to level 2. $H R R_{1 \rightarrow 2}$ is the time-resolved HRR measured by the calorimeter, $k$ is the calorimeter time constant (the inverse of the response time), and $t$ is the time since the HRR change. The experimental time constant was estimated by rapidly inserting and removing a small flame under the cone calorimeter to create nearly instantaneous HRR changes between two known levels at well-defined times. A series of calculated $H R R_{1 \rightarrow 2}$ curves were then generated using a range of $k$ values. The value of $k$ that resulted in the best agreement between the calculated $H R R_{1 \rightarrow 2}$ curves and the experimentally measured HRR profile was identified as the effective cone calorimeter first order time constant. The result was $0.20 \mathrm{~s}^{-1}$.

Once the value of $k$ was available, a continuous experimentally measured HRR temporal profile could be corrected using an equation of the form

$H R R_{\text {corr }}(t)=k \frac{d\left(H R R_{\text {meas }}(t)\right)}{d t}+\left(H R R_{\text {meas }}(t)\right)$,

which for a digitized time series recorded at $1 \mathrm{~Hz}$ can, as in the current experiments, can be approximated as

$H R R_{\text {corr }}\left(t_{i+1}\right)=\frac{1}{\left(1-e^{-k}\right)}\left(H R R_{\text {meas }}\left(t_{i+1}\right)-H R R_{\text {meas }}(t)\right)+H R R_{\text {meas }}(t)$

with $H R R_{\text {corr }}(0)=H R R_{\text {meas }}(0)$.

The time derivative of the measured HRR curve magnifies any noise present in the experimental data which is introduced into the corrected HRR temporal profile. Often, additional analysis steps, such as smoothing of the experimental data, are applied to limit such noise. Since the focus here is on relatively large HRR changes over short periods of time, no smoothing of the experimental data was used.

\subsubsection{Parameters to characterize HRR temporal profiles}

Typical cone calorimetry parameters used to characterize temporal profiles of HRR and sample mass include ignition time, time to and value of PHRR, total heat released (THR), and total mass loss of the sample.

As discussed below, three peaks were identified in many of the HRR time profiles measured in this study. In order to better characterize these HRR temporal profiles, the times to and magnitudes of the three HRR peaks were recorded when appropriate. In the cases where a 
well-defined second peak was not identified but where a HRR shoulder on the first peak could be discerned, the maximum HRR value at the shoulder of the HRR curve was reported. A derived property known as the fire growth rate (FIGRA) index is calculated by dividing the HRR by the time since sample exposure [53]. The FIGRA index was originally introduced for the classification of building products tested using the Single Burning Item (SBI) test [54]. Lower values of FIGRA are associated with improved flammability behavior since lower HRR peaks and slower fire growth times are desirable. Where possible, three times to and peak FIGRA values were determined to characterize the resulting FIGRA temporal profiles in the same way as for the HRR time profiles.

\subsubsection{Thermocouple measurements}

Three sheathed TCs (Chromel-Alumel, Type K, grounded, probe diameter $=0.5 \mathrm{~mm}$; KMQXL-020G-12, Omega Engineering, Inc.) were connected to wireless TC transmitters (MWTC-D-K-915) mounted on the cone calorimeter sample holder (to eliminate the need for direct wire connections, which can interfere with accurate sample mass measurements). Each transmitter updates its temperature reading every $2 \mathrm{~s}$. A single USB-based wireless receiver (MWTC-REC5-915) is used to couple the temperature measurements to the data acquisition computer. Note that even though the cone data were recorded at $1 \mathrm{~Hz}$, temperature readings were only updated every two seconds. The TCs were positioned within the FPUF at three depths ( $5 \mathrm{~mm}, 25 \mathrm{~mm}$, and $45 \mathrm{~mm}$ ) along a line running from the top to the bottom at the center of the FPUF sample. Each TC was placed inside a hollow needle which was inserted from the side of the sample. When the TC was positioned at the desired position, the needle was withdrawn. The standard uncertainty in TC placement is estimated to be $\pm 2 \mathrm{~mm}$. Fig. 1 indicates the TC positions.

TCs have been extensively used to measure temperature in fire environments. However, it must be kept in mind that the temperature recorded by a TC is not necessarily that in the media immediately surrounding the sensor. In the absence of temporal variations, the temperature of the TC sensor is controlled by a balance of heat flow to and from the sensor by convection, conduction, and radiation [55]. In addition, due to its thermal inertia, a TC also has a finite time response that varies depending on the same heat transfer processes. Due to these complications, it is unlikely that the temperatures recorded by the TCs in these experiments corresponded to those of the surrounding media. Nonetheless, as shown below, the TC response does provide valuable insights into the stages of FPUF decomposition during the experiments.

\section{Results and Discussion}

\subsection{Reproducibility of HRR Temporal Profiles}

Generally, the reproducibility of cone calorimetric data for highly flammable combustible materials is good $[47,48]$. However, for the composites considered in this study, which include BFs that have the potential to significantly improve flammability behavior by various mechanisms, it is important to assess the degree of reproducibility for repeated tests. The improved flammability behavior with reduced HRR levels might show more variability in 
HRR profiles. It is therefore considered important to assess the degree of reproducibility for repeated tests.

Examples of the reproducibility of HRR temporal profiles for FPUF and FPUF/BF composites with highloft, flat-permeable, and flat impermeable barriers are shown in Fig. 2. The time profiles for the three tests with FPUF alone are very similar in shape and magnitude. On the other hand, it is evident that while the overall shapes of the HRR curves are similar for a given type of composite, variations in both the times and magnitudes of local maxima are more variable than observed for FPUF alone. In general, the variations are largest at longer times and, particularly so, when flame extinction and reignition were observed, as in the repeated tests with FPUF/BF-15 and FPUF/BF- 20. As discussed below, times to and values of local maxima were determined as part of the analysis. The magnitudes of the standard deviations for the averages for local maxima reflect such variations.
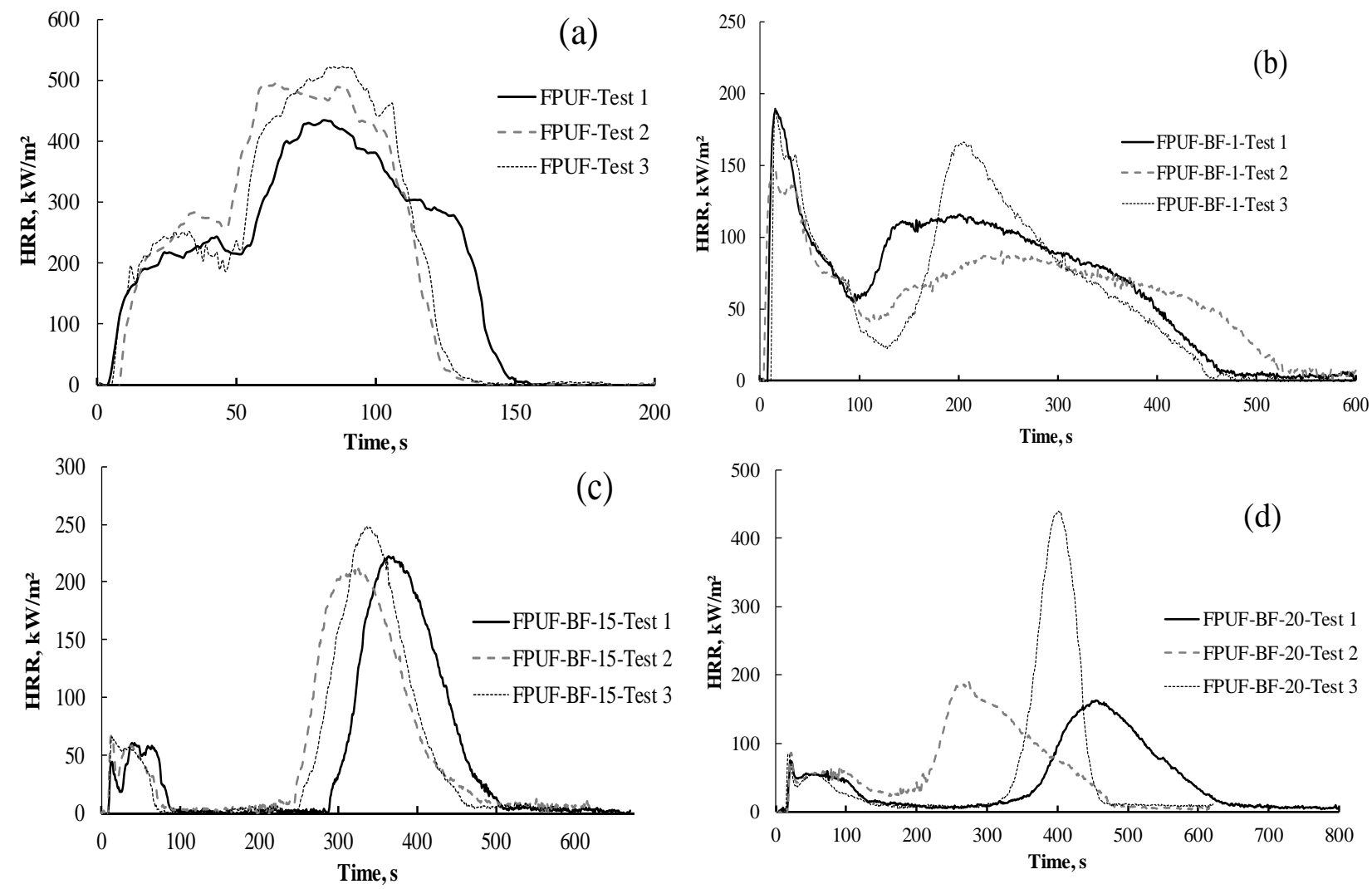

Fig. 2. Reproducibility data examples for (a) FPUF and FPUF/BF composites with (b) highloft BF, (c) flat permeable BF, and (d) flat impermeable BF.

\subsection{Corrected Time Response HRR Data}

As noted in Section 2.2.6, HRR temporal profiles for materials such as those considered in the current study can be distorted from the actual time behavior due to time response effects. For the rapid HRR rise times and sharp peaks observed in some of the current experiments, measured values of peak HRR are expected to be underestimated with the times required to reach the maximum value overestimated [52]. Examples of measured HRR temporal profiles for FPUF and FPUF/BF composites with BF-5 and BF-19 are shown in Fig. 3 along with 
individual profiles corrected using Eq. (3). As mentioned earlier, the correction of HRR data for time response effects amplifies noise in the HRR data. Ignoring the increased noise, significant differences between the two curves when the measured HRR changes rapidly are evident. These differences are particularly apparent following ignition when the HRR abruptly increases. For the FPUF sample the result is a faster HRR growth to a plateau value. The time-response corrections are more significant for the two composites which have sharp HRR
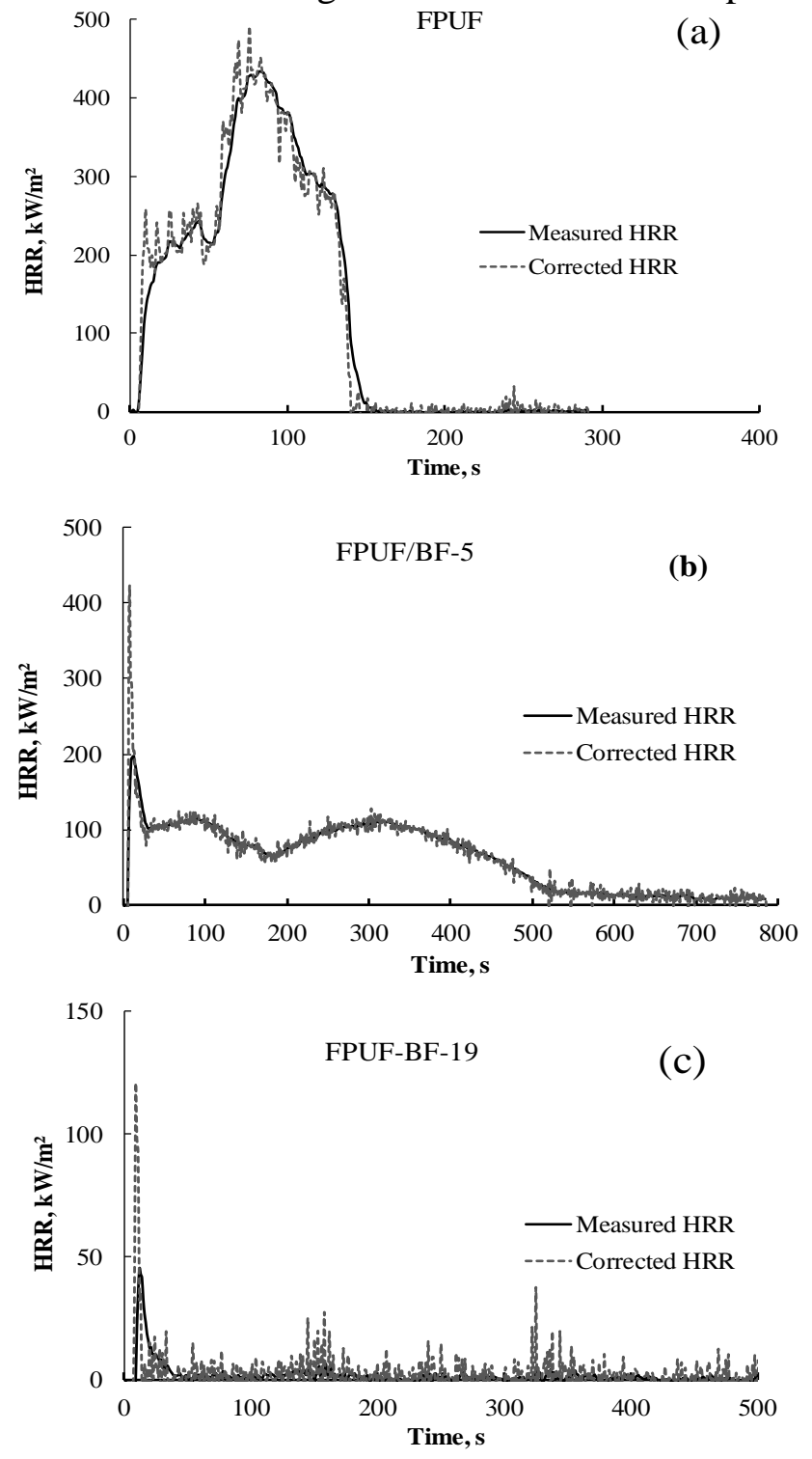

peaks following ignition. The sizes of the peaks in these cases are roughly doubled and move to earlier times, indicating the importance of correcting for time response.

Fig. 3. Measured and corrected HRR temporal profiles for (a) FPUF and (b) FPUF/BF-5 and (c) FPUF/BF-19 composites. 
Table 2. Comparison of the measured and corrected PHRR values for initial peaks in HRR curves (PHRR $\mathrm{BF}_{\mathrm{BF}}$ ) and corresponding times to peak (TTP $\left.\mathrm{BF}_{\mathrm{BF}}\right)$ for FPUF/BF composites.

Uncertainties are reported as experimental standard deviations.

\begin{tabular}{|l|r|r|r|r|r|r|}
\hline \multirow{2}{*}{ Sample ID } & \multicolumn{3}{|c|}{ PHRR $_{\text {BF }},\left(\mathbf{k W} / \mathbf{m}^{\mathbf{2}}\right.$ ) } & \multicolumn{3}{c|}{ TTP } \\
& Measured & (s) \\
\hline FPUF/BF-1 & $177 \pm 32$ & \multicolumn{1}{|c|}{ Corrected } & \% Change & Measured & Corrected & \%Change \\
\hline FPUF/BF-2 & $186 \pm 44$ & $427 \pm 128$ & +130 & $11 \pm 0$ & $3 \pm 1$ & -8 \\
\hline FPUF/BF-4 & $160 \pm 36$ & $361 \pm 69$ & +126 & $12 \pm 2$ & $4 \pm 1$ & -8 \\
\hline FPUF/BF-5 & $184 \pm 7$ & $422 \pm 63$ & +129 & $12 \pm 3$ & $5 \pm 1$ & -7 \\
\hline FPUF/BF-8 & $176 \pm 6$ & $306 \pm 29$ & +74 & $21 \pm 3$ & $11 \pm 3$ & -10 \\
\hline FPUF/BF-9 & $112 \pm 13$ & $301 \pm 46$ & +169 & $20 \pm 5$ & $12 \pm 4$ & - \\
\hline FPUF/BF-10 & $172 \pm 28$ & $370 \pm 60$ & +115 & $21 \pm 1$ & $16 \pm 2$ & -5 \\
\hline FPUF/BF-13 & $180 \pm 5$ & $322 \pm 21$ & +89 & $26 \pm 1$ & $18 \pm 1$ & -8 \\
\hline FPUF/BF-14 & $136 \pm 14$ & $257 \pm 19$ & +89 & $28 \pm 4$ & $20 \pm 1$ & -8 \\
\hline FPUF/BF-15 & $57 \pm 3$ & $166 \pm 32$ & +182 & $23 \pm 11$ & $9 \pm 1$ & -14 \\
\hline FPUF/BF-16 & $189 \pm 12$ & $310 \pm 48$ & +64 & $16 \pm 1$ & $12 \pm 1$ & -4 \\
\hline FPUF/BF-19 & $45 \pm 2$ & $102 \pm 10$ & +127 & $13 \pm 1$ & $8 \pm 2$ & -5 \\
\hline FPUF/BF-20 & $56 \pm 3$ & $209 \pm 37$ & +273 & $21 \pm 3$ & $16 \pm 2$ & -5 \\
\hline FPUF/BF-21 & $109 \pm 13$ & $199 \pm 49$ & +83 & $24 \pm 4$ & $13 \pm 7$ & -11 \\
\hline FPUF/BF-23 & $260 \pm 4$ & $373 \pm 13$ & +43 & $41 \pm 3$ & $35 \pm 4$ & -6 \\
\hline FPUF/BF-24 & $877 \pm 18$ & $883 \pm 44$ & +1 & $50 \pm 1$ & $61 \pm 1$ & -11 \\
\hline
\end{tabular}

The sharp peaks at earlier times seen for many of the FPUF/BF composites are associated primarily with flash burning of the BF, even though some underlying HRR contribution from FPUF pyrolysis is likely. Table 2 compares averages and standard deviations for times (denoted TTP $\mathrm{BF}_{\mathrm{BF}}$ ) and magnitudes (denoted PHRR $\mathrm{BF}_{\mathrm{BF}}$ ) of measured initial HRR maxima with those determined from HRR profiles corrected for time response for repeated FPUF and FPUF/BF composite tests. Values of time differences and percentage changes in measured

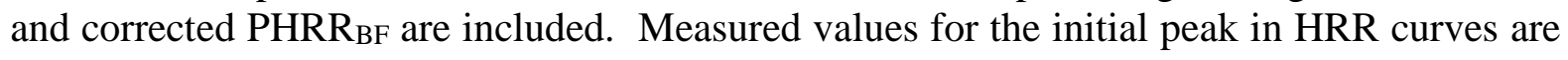
underestimated by $40 \%$ to $270 \%$ and the times to peak $\left(\mathrm{TTP}_{\mathrm{BF}}\right)$ are overestimated by $4 \mathrm{~s}$ to $14 \mathrm{~s}$, depending on the burning behavior of the BF. The standard deviations for PHRR $\mathrm{BF}_{\mathrm{B}}$ are substantially higher for the corrected PHRR $\mathrm{BF}_{\mathrm{BF}}$ values, while those for $\mathrm{TTP}_{\mathrm{BF}}$ are little affected. Generally, the percentage changes in corrected PHRR $\mathrm{BF}_{\mathrm{B}}$ values are lower when TTPs are higher. These findings confirm the need for time response corrections when rapid changes in HRR occur.

Fig. 4 (a) shows flash flaming ignition of one of the FPUF/BF-19 composites at $7 \mathrm{~s}$. The initial peak of $99 \mathrm{~kW} / \mathrm{m}^{2}$ occurred at $8 \mathrm{~s}$ when the HRR data was corrected for the response time of the cone calorimeter. Fig. 4 (b) shows the corresponding image at $13 \mathrm{~s}$, which is when the uncorrected HRR data indicated the initial peak $\left(45 \mathrm{~kW} / \mathrm{m}^{2}\right)$ occurred. As is evident, at this time the flames had already extinguished. These images provide a striking confirmation that failure to consider cone calorimeter time response effects can result in serious misinterpretation of burning behavior when rapid HRR changes occur. 

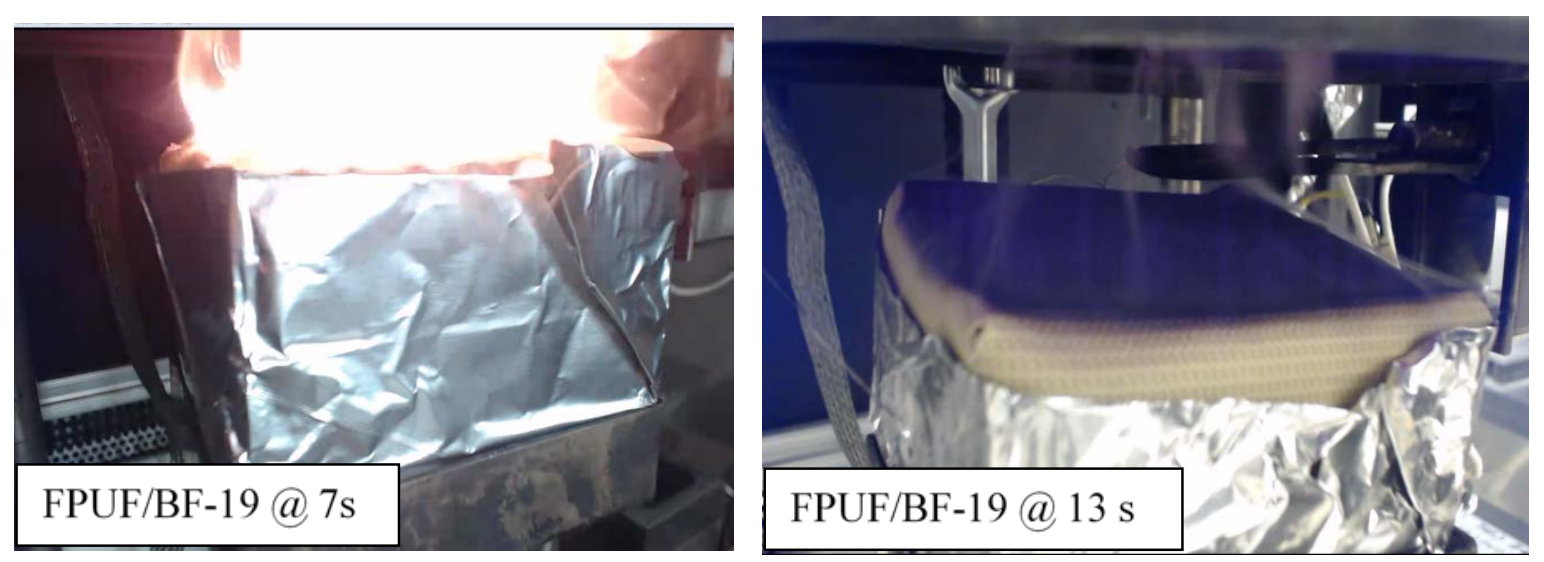

Fig. 4. (a) Flash-flaming ignition of BF-19 at $7 \mathrm{~s}$ and (b) flame out at $13 \mathrm{~s}$.

\subsection{Burning Behavior of Flexible Polyurethane Foam}

Examples of the HRR curves recorded for uncovered FPUF specimens in aluminum pans and placed on either a ceramic wool or a Marinite ${ }^{\circledR}$ board substrates are shown in Fig. 5. While the sample on the insulating ceramic wool shows two distinct HRR peaks, with the second considerably higher, the profile for the sample on the Marinite substrate grows rapidly to an initial peak of similar magnitude and shape, but then maintains a roughly constant HRR, while burning for a substantially longer time. These observations suggest that FPUF pyrolysis involves a two-stage process which is initially insensitive to the underlying substrate material but becomes strongly dependent on the substrate at later times.

Similar two-stage burning of FPUF samples in cone calorimetry experiments has been noted by numerous researchers and attributed to a two-stage pyrolysis of the foam [52, 56-60]. Ravey and Pearce [57] provided a detailed discussion of the two-stage pyrolysis. The origin lies in the use of toluene diisocyante (TDI) and polyether-based polyols as the primary ingredients in FPUF typically used in American RUF. Even though the reaction chemistry is complex, resulting in the formation of an expanded complex polymeric structure with a variety of bond types including urethane, urea, biuret, and allophanate (the relative fractions depend on the foaming conditions), its general thermal decomposition behavior is relatively simple.

Each of the bond types created by the reactions between the diisocyanate and polyol decompose at temperatures around $225^{\circ} \mathrm{C}$ to release molecules derived from the original TDI and high molecular weight polyol. The molecules derived from TDI have relatively low molecular weights and thus gasify and escape from the remaining foam, while the higher molecular weight material derived from the polyol is left behind. The polyol-derived materials tend to be liquid and to remain stable up to temperatures on the order of $325{ }^{\circ} \mathrm{C}$ before beginning to pyrolyze. Since both pyrolysis processes are endothermic, the pyrolysis occurs in two distinct steps. As a foam sample is heated it immediately begins to collapse as the TDIbased molecules are released. The surface temperature remains roughly constant due to the heat absorbed by the decomposing bonds. The foam collapse continues until the entire structure is degraded. At this point the remaining material has collapsed into a much thinner liquid layer. 


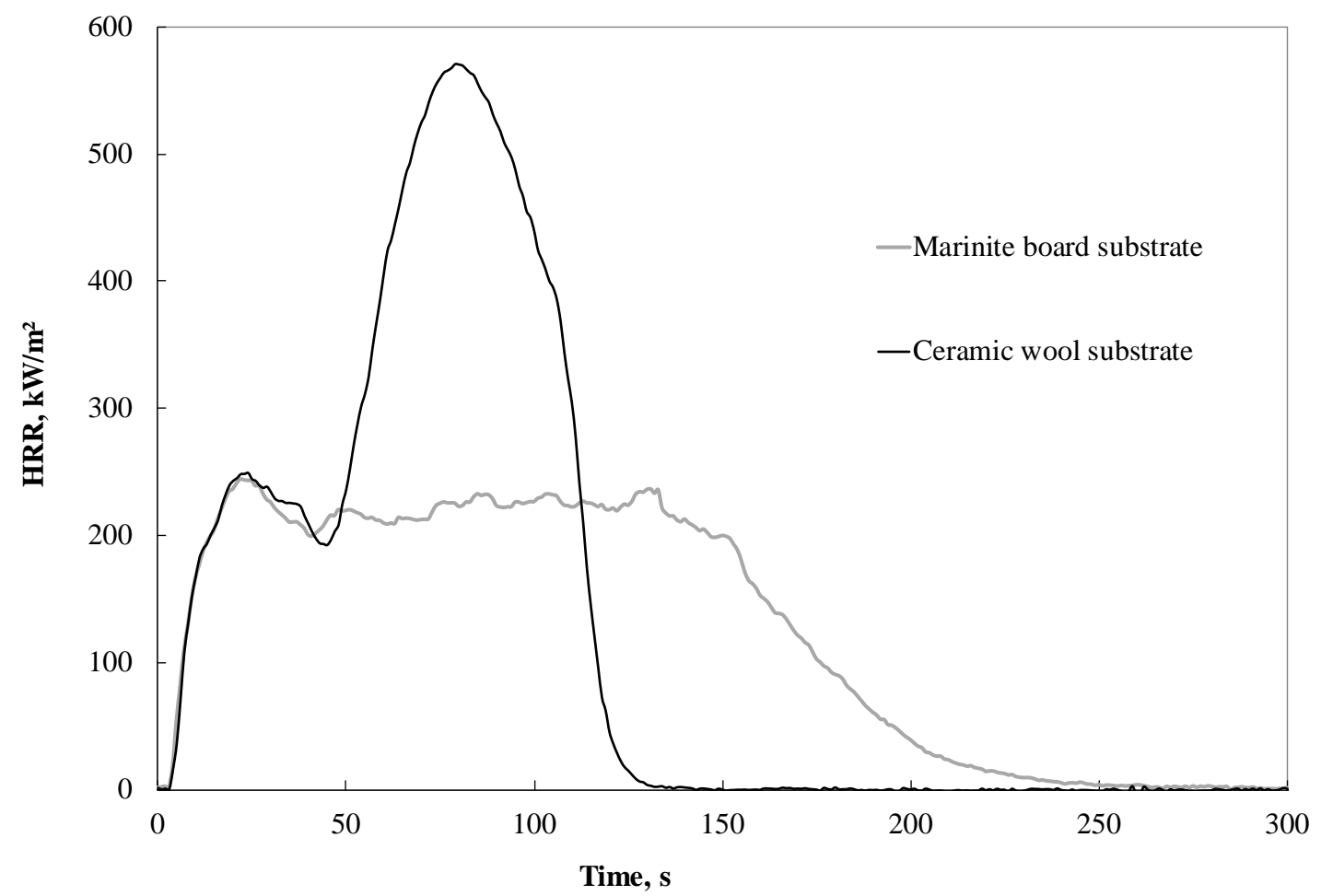

Fig. 5. Heat release data for FPUF with different sample holder substrates.

Once the first stage of pyrolysis is complete, additional heating of the polyol-derived material can increase its temperature to a point where it begins to pyrolyze and produce additional flammable gases.

This pyrolysis model provides an explanation for the behaviors evident in Fig. 5. For both sample configurations the initial peak in the HRR is associated with the breaking of the bonds involving the TDI-derived materials during the first stage of pyrolysis. Since the FPUF decomposes from the top down, the remaining unreacted foam serves to insulate the collapsing foam from the bottom of the aluminum pan in contact with the substrate. As a result, the initial HRR curves are very similar. In contrast, after the foam fully collapses, the very-thin liquid layer of polyol-derived material is deposited on the bottom of the pan. This thin layer has a much higher thermal conductivity than the original foam, and its narrow depth ensures a nearly uniform temperature throughout the liquid. Once the liquid is heated to a temperature sufficient to induce pyrolysis, additional heating will generate the combustion gases supporting the second stage of burning. The strong dependence on sample substrate arises because the collapsed liquid is in intimate contact with the bottom of the highly thermally conductive aluminum pan, which is, in turn, in strong thermal contact with the underlying substrate. Owing to lower thermal inertia, Marinite extracts more heat from the liquid than the ceramic wool, thus lowering the heat available to induce pyrolysis and thereby reducing the HRR of the second stage burning, as observed.

Although it is well established that the rate of pyrolysis is an important feature resulting from the thermal behavior of a specimen [60], one of the objectives of this work was to select a 
sample configuration for quantitative comparison of composites with different BFs subject to intense fire conditions. A ceramic wool substrate was chosen for the composite experiments because it was expected to result in more intense burning of the polyol-derived liquid. Considering a worst case scenario in a real fire exposure, the more intense burning of the polyol-derived liquid was studied in the presence of ceramic wool substrate.

\subsection{Thermocouple Measurements in FPUF/BF Composites}

In the cone calorimeter, FPUF pyrolysis is expected to proceed from top to bottom due to heating from above by cone thermal radiation and heat transfer from any flames. Since the FPUF is a highly insulating material, decomposition takes place in a thin interfacial layer where TDI-derived species are released, and liquid derived from polyol is deposited on the freshly exposed FPUF [57]. This process continues until all of the foam has collapsed, and a thin layer of liquid derived from polyol is deposited at the bottom of the aluminum pan.

The TCs inserted into the FPUF provide a means to characterize the foam collapse. The recorded TC temperatures may not correspond to the temperatures of the medium immediately surrounding the TC due to radiative and convective heat transfer effects. The temperaturetime data do, however, provide useful insights into the collapse behavior of FPUF. Fig. 6 shows temperature-time profiles for the three TCs located at the top (5 $\mathrm{mm}$ from top), middle (25 mm) and bottom (45 mm) of the FPUF block for FPUF alone (a) and exemplar composites with permeable highloft (b), permeable flat (c), and impermeable flat barrier fabrics (d). Temperature profiles for the TCs, particularly after the FPUF has collapsed, are inconsistent and show uneven changes in temperatures. This is probably because the TCs are no longer within the FPUF and have poor thermal contact with the gaseous pyrolyzates and/or flames.

Even though the shapes and magnitudes of the temperature profiles vary with TC location within a given composite and between the different composites, each of the temperature profiles shows a common behavior. At the start of the experiment the TCs read room temperature. After a delay time, which increases with TC depth, the measured temperature begins to increase slowly. This period of relatively slow temperature increase is followed by a well-defined and abrupt jump in the rate of temperature increase, with measured temperatures rising to values between $300{ }^{\circ} \mathrm{C}$ and $700{ }^{\circ} \mathrm{C}$. Generally, the periods required to reach the temperature break point increase with TC depth for a given sample. The well-defined break point and subsequent rapid temperature increase are indications that heat transfer to the TC at the measurement location has abruptly increased. A reasonable explanation for this behavior is that the initial slow temperature increase is due to relatively low levels of heat transfer through the foam from the FPUF pyrolysis zone as it approaches the TC. When the pyrolysis zone recedes pass the TC, the TC is no longer surrounded by FPUF and is directly exposed to heating from above. Thus, the break points in the temperature curves are indications of the times when the FPUF pyrolysis front passes the TC locations.

By identifying the break-point times from the TC time profiles, it was possible to determine the times when the receding foam pyrolysis front passed locations at the center of foam block at depths of $5 \mathrm{~mm}, 25 \mathrm{~mm}$, and $45 \mathrm{~mm}$. Table 3 lists the results of experiments with 
unprotected FPUF and composites protected with fire-blocking BFs grouped as highloft, permeable; flat, permeable; and flat, impermeable. Generally, measurements with TCs in place were repeated 3 times for FPUF samples, but only once for the composites. Note that the BF10 composite was not tested with TCs in place. The table also includes values of characteristic recession velocities as the pyrolysis front moves between the $5 \mathrm{~mm}$ and $25 \mathrm{~mm}$ TCs $\left(\mathrm{V}_{\text {top }}\right)$, the $25 \mathrm{~mm}$ and $50 \mathrm{~mm}$ TCs ( $\mathrm{V}_{\text {bottom}}$ ) and the $5 \mathrm{~mm}$ and $50 \mathrm{~mm}$ TCs ( $\mathrm{V}_{\text {average}}$ ), determined by dividing the distance traveled by the period required.
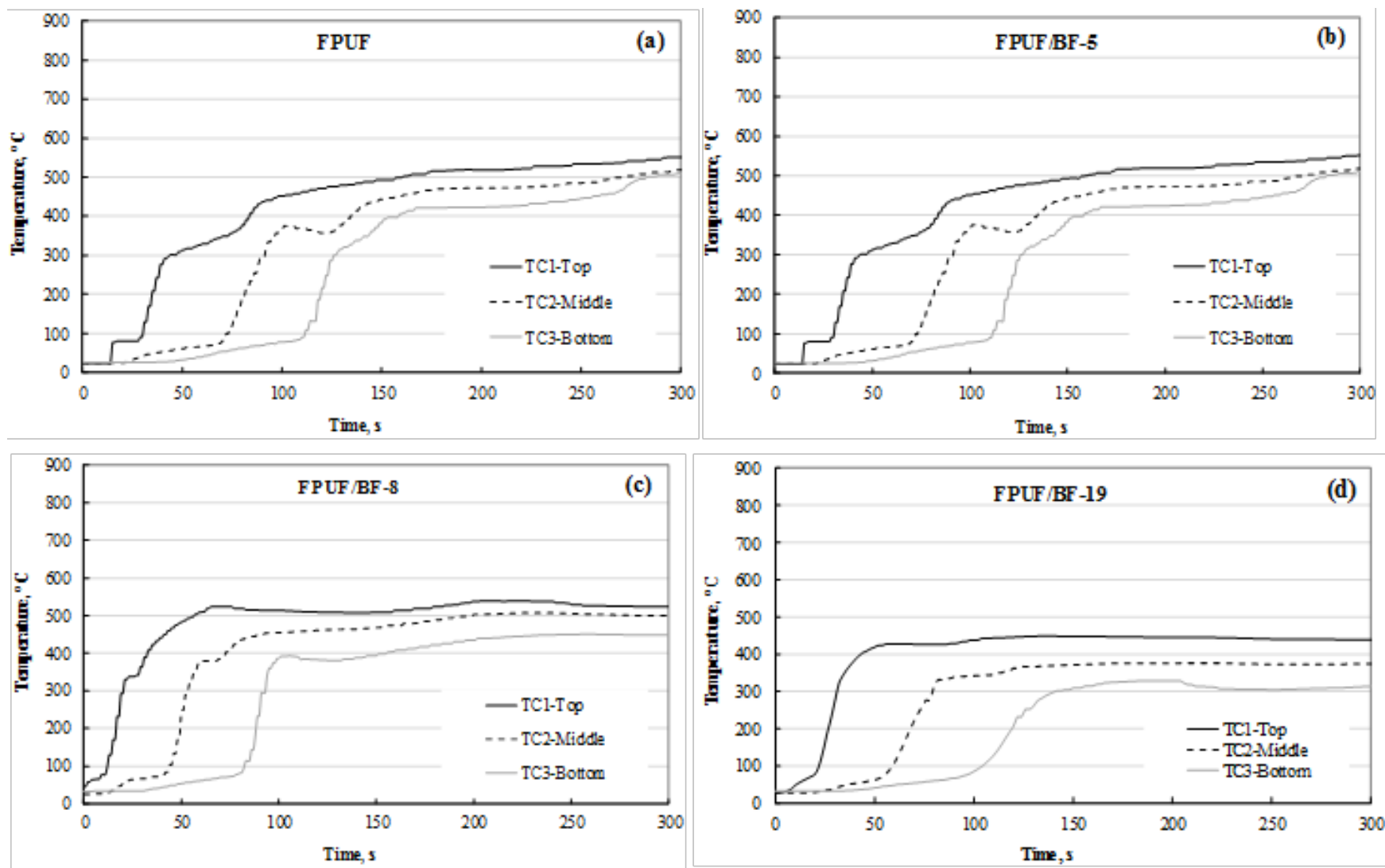

Fig. 6. Top, middle and bottom TC measurements within the (a) FPUF, (b) FPUF/BF-5, (c) FPUF/BF-8, and (d) FPUF/BF-19. 
Table 3. Times at which the pyrolysis front passes over top, middle and bottom TCs and collapse rates of FPUF within FPUF/BF ${ }^{\S}$ composites exposed to $35 \mathrm{~kW} / \mathrm{m}^{2}$ heat flux in the cone calorimeter. Variations among repeated FPUF samples are reported as experimental standard deviations. Barriers are grouped as highloft, flat-permeable, and flat impermeable.

\begin{tabular}{|c|c|c|c|c|c|c|}
\hline \multirow{2}{*}{ Sample } & \multicolumn{3}{|c|}{ Time, $s$} & \multicolumn{3}{|c|}{ Collapse rate of FPUF, $\mathrm{mm} / \mathrm{s}$} \\
\hline & Top TC & Middle TC & Bottom TC & $V_{\text {top }}$ & Vbottom & Vaverage \\
\hline FPUF & $7 \pm 1$ & $11 \pm 2$ & $29 \pm 2$ & $5.8 \pm 3.8$ & $1.2 \pm 0.1$ & $1.8 \pm 0.1$ \\
\hline FPUF/BF-1 & 12 & 28 & 40 & 1.3 & 1.7 & 1.4 \\
\hline FPUF/BF-2 & 22 & 56 & 70 & 0.6 & 1.4 & 0.8 \\
\hline FPUF/BF-4 & 24 & 54 & 118 & 0.7 & 0.3 & 0.4 \\
\hline FPUF /BF-5 & 30 & 70 & 108 & 0.5 & 0.5 & 0.5 \\
\hline FPUF/BF-24 & 11 & 21 & 31 & 1.8 & 1.3 & 1.2 \\
\hline FPUF/BF-8 & 19 & 53 & 83 & 0.6 & 0.7 & 0.6 \\
\hline FPUF/BF-9 & 15 & 45 & 69 & 0.7 & 0.8 & 0.7 \\
\hline FPUF/BF-10* & NA & NA & NA & NA & NA & NA \\
\hline FPUF/BF-13 & 28 & 40 & 80 & 1.7 & 0.5 & 0.8 \\
\hline FPUF/BF-14 & 24 & 80 & 122 & 0.4 & 0.5 & 0.4 \\
\hline FPUF/BF-15 & 16 & 20 & 58 & 5.0 & 0.5 & 0.9 \\
\hline FPUF/BF-16 & 16 & 44 & 92 & 0.7 & 0.4 & 0.5 \\
\hline FPUF/BF-21 & 20 & 34 & 56 & 1.4 & 0.9 & 1.1 \\
\hline FPUF/BF-19 & 14 & 52 & 102 & 0.5 & 0.3 & 0.4 \\
\hline FPUF/BF-20 & 26 & 48 & 64 & 0.9 & 1.3 & 1.1 \\
\hline FPUF/BF-23 & 34 & 70 & 96 & 0.6 & 0.8 & 0.7 \\
\hline
\end{tabular}

${ }^{\S}$ Uncertainty data for FPUF/BF composites is not available as only one measurement was taken.

* Not Tested, NA = not available. 

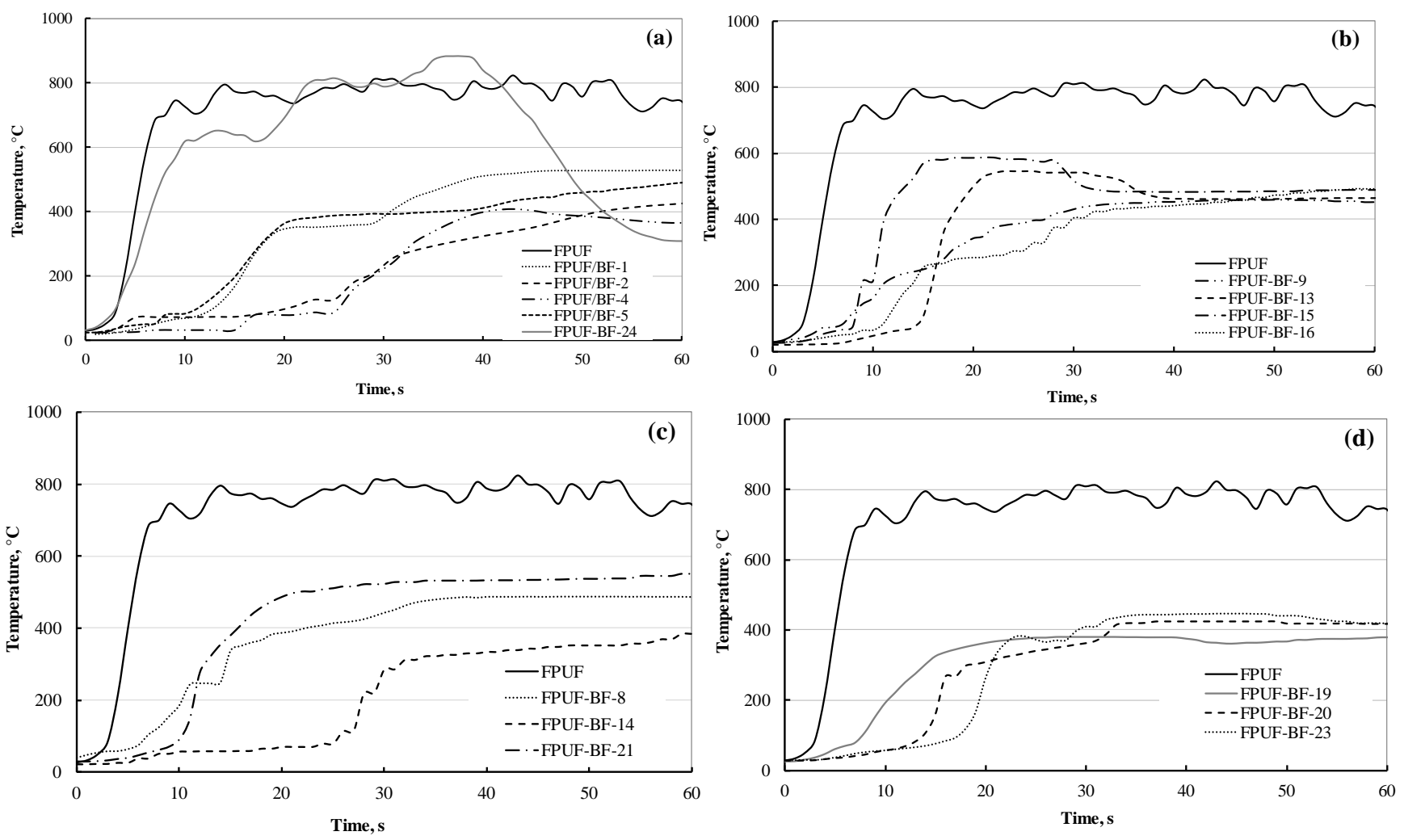

Fig. 7. Comparison of characteristic time-temperature profiles recorded by the top TC for bare FPUF and FPUF/BF composites with (a) highloft, permeable BFs, (b) flat, permeable, and self-extinguishing BFs, (c) flat, permeable BFs and (d) flat, impermeable BFs.

\subsection{Burning Behavior of FPUF/BF Composites}

Characteristics describing the general burning behavior of the FPUF and FPUF/BF composites are summarized in Table 4. Burning behavior of FPUF and FPUF/BF composites in the cone calorimetry tests and description of sample residue. Uncertainties are reported as experimental standard deviations. Numbers in parentheses represent occurrence of events per repeated tests.. Included are the time to ignition (TTI) following initial exposure, whether or not flame extinction was observed prior to fuel depletion and, if so, the period required for reignition in the presence of the spark igniter, the duration of the flaming, and descriptions of barrier condition and any FPUF residue following the end of a test. The temporal profiles of HRR and sample mass for the FPUF/BF composites are shown in Fig. 8 (composites with highloft BFs), Fig. 9 (composites with flat permeable BFs showing flame extinction), Fig. 10 (composites with flat permeable BFs not showing flame extinction), and Fig. 11 (composites with flat impermeable BFs).

There are three distinct maxima in the HRR curves for many of the BF composites (BF-2, BF4, BF-5, BF-8, BF-9, BF-14, BF-15, and BF-20). Based on the expected burning behaviors of the barriers and the FPUF, it is reasonable to associate these peaks with sequential burning of the barrier $\left(\mathrm{PHRR}_{\mathrm{BF}}\right)$, pyrolozate of species derived from the TDI component of the foam $\left(\mathrm{PHRR}_{1}\right)$, and pyrolyzate of species derived from the polyol component of the foam $\left(\mathrm{PHRR}_{2}\right)$. 
Note that numbered subscripts are used to emphasize the correspondence to the two peaks observed when FPUF is tested alone.

Table 4. Burning behavior of FPUF and FPUF/BF composites in the cone calorimetry tests and description of sample residue. Uncertainties are reported as experimental standard deviations. Numbers in parentheses represent occurrence of events per repeated tests.

\begin{tabular}{|c|c|c|c|c|c|c|}
\hline \multirow[t]{2}{*}{ Sample } & \multirow[t]{2}{*}{ TTI, s } & \multirow[t]{2}{*}{$\begin{array}{c}\text { Flame } \\
\text { extinction }\end{array}$} & \multirow[t]{2}{*}{$\begin{array}{l}\text { Time to re- } \\
\text { ignition, s }\end{array}$} & \multirow{2}{*}{$\begin{array}{c}\text { Duration } \\
\text { of } \\
\text { flaming, s } \\
\end{array}$} & \multicolumn{2}{|c|}{$\begin{array}{c}\text { Description of sample } \\
\text { residue }^{\S} \\
\end{array}$} \\
\hline & & & & & BF char & FPUF \\
\hline FPUF & $4 \pm 1$ & No & - & $132 \pm 12$ & - & $\begin{array}{l}\text { No char, } \\
\text { FPUF burns } \\
\text { completely }\end{array}$ \\
\hline FPUF/BF-1 & $6 \pm 3$ & No & - & $396 \pm 60$ & Intact & Negligible \\
\hline FPUF/BF-2 & $4 \pm 1$ & No & - & $570 \pm 30$ & Intact & Negligible \\
\hline FPUF/BF-4 & $3 \pm 1$ & No & - & $552 \pm 6$ & Intact & Negligible \\
\hline FPUF/BF-5 & $4 \pm 1$ & No & - & $504 \pm 6$ & Intact & Negligible \\
\hline FPUF/BF-8 & $9 \pm 3$ & No & - & $558 \pm 78$ & Intact & Negligible \\
\hline FPUF/BF-10 & $13 \pm 1$ & No & - & $402 \pm 198$ & Cracks & Negligible \\
\hline FPUF/BF-14 & $13 \pm 9$ & No & - & $414 \pm 78$ & Intact & Negligible \\
\hline FPUF/BF-21 & $9 \pm 3$ & No & - & $360 \pm 12$ & Cracks & Negligible \\
\hline FPUF/BF-24 & $8 \pm 0$ & No & - & $138 \pm 12$ & $\begin{array}{l}\text { Melts } \\
\text { away }\end{array}$ & Negligible \\
\hline FPUF/BF-9 & $10 \pm 1$ & Yes (2/4) & $100 \pm 10(2 / 2)$ & $396 \pm 30$ & Intact & Negligible \\
\hline FPUF/BF-13 & $15 \pm 1$ & Yes (3/4) & $164 \pm 14(3 / 3)$ & $324 \pm 54$ & Intact & Negligible \\
\hline FPUF/BF-15 & $9 \pm 1$ & Yes (4/4) & $140 \pm 10(4 / 4)$ & $336 \pm 36$ & Intact & Negligible \\
\hline FPUF/BF-16 & $5 \pm 3$ & Yes $(2 / 4)$ & $\begin{array}{r}\text { No re-ignition } \\
(0 / 2)\end{array}$ & $210 \pm 54$ & Intact & Significant \\
\hline FPUF/BF-19 & $7 \pm 2$ & Yes (4/4) & $\begin{array}{r}\text { No re-ignition } \\
(0 / 4)\end{array}$ & $<6$ & Intact & Significant \\
\hline FPUF/BF-20 & $16 \pm 2$ & Yes (2/3) & $108 \pm 73(2 / 2)$ & $527 \pm 164$ & Intact & Negligible \\
\hline FPUF/BF-23 & $20 \pm 3$ & Yes (4/4) & $258 \pm 90(3 / 4)$ & $192 \pm 144$ & Intact & Significant \\
\hline
\end{tabular}

$\S$ Negligible: FPUF residue $\leq 10 \%$ of original FPUF mass, Significant: FPUF residue $\geq 50 \%$ of original FPUF mass.

The above burning model is idealized, and in reality, burning of the three types of fuel are likely to overlap somewhat in time. However, for a given local HRR maximum it is expected that the associated fuel type will be the dominant contributor. Some support for this conclusion is obtained by indicating the times when the pyrolysis front passes the three TCs on the HRR plots with "x"s and adding vertical dashed lines at these times. The time when the pyrolysis front passed the third TC and the remaining sample mass percentage at this time are also indicated.

Review of the HRR results having three distinct peaks indicates that the times when the pyrolysis front passed the location $5 \mathrm{~mm}$ from the top of the FPUF block are very similar to the times for the initial peaks. The behavior is consistent with these peaks being due primarily 
to flash burning of the barriers. The second peaks all occurred when the pyrolysis front was located between $5 \mathrm{~mm}$ from the top and $5 \mathrm{~mm}$ from the bottom of the foam. This behavior is consistent with these peaks being primarily due to burning of TDI-derived pyrolyzate. In all cases, the third peak occurred well after the receding FPUF pyrolysis front passed below the location $5 \mathrm{~mm}$ above the base of the foam block. This behavior provides strong evidence that these peaks were associated with burning of pyrolyzate from the liquid deposited on the bottom of the pan.
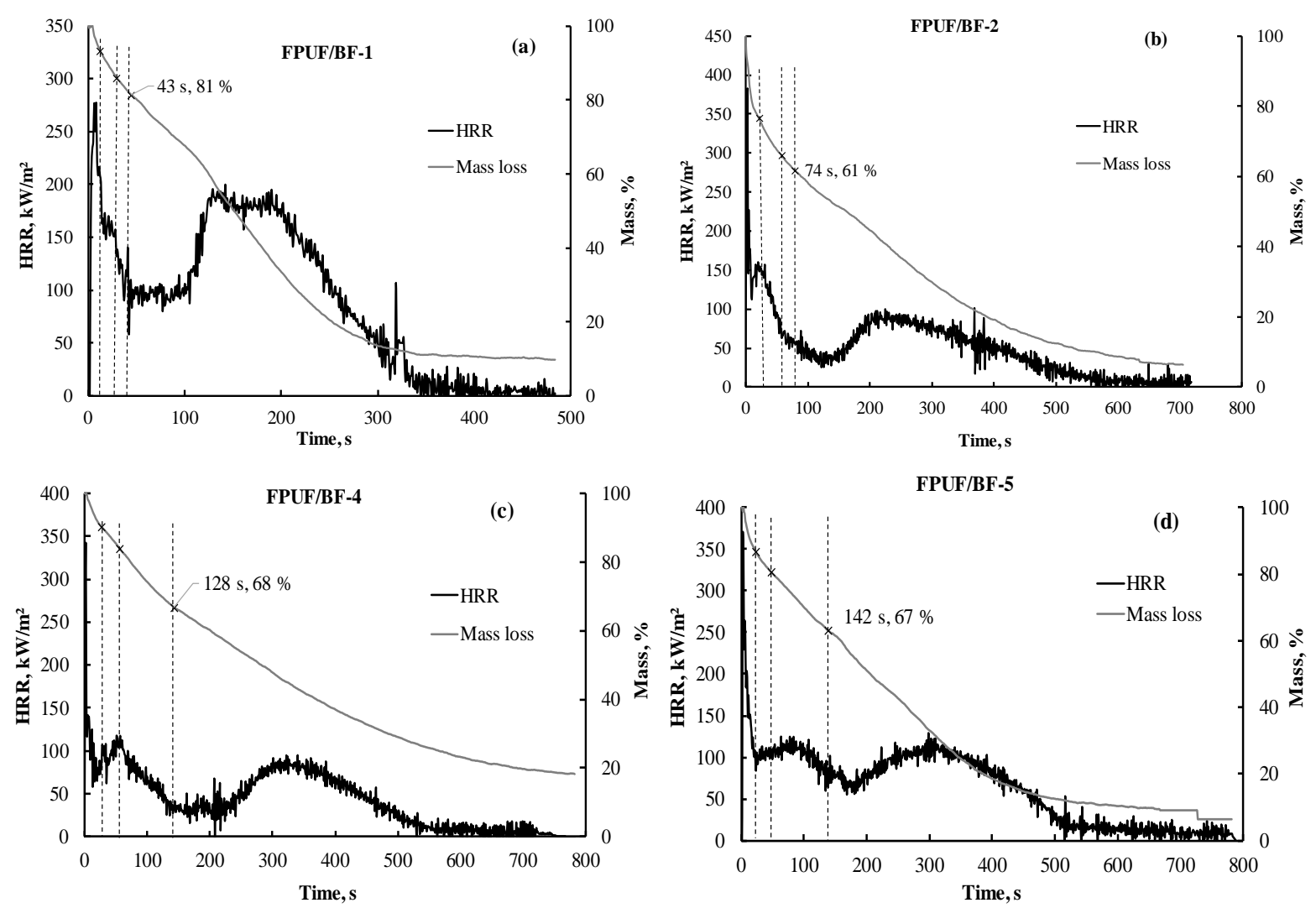

FPUF/BF-24

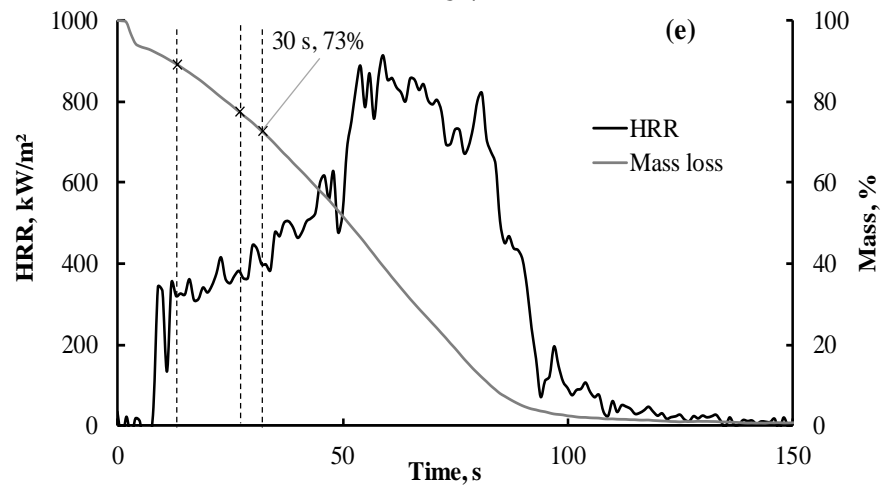

Fig. 8. Heat release rate and mass loss data for FPUF/BF composites with highloft barriers: (a) BF-1, (b) BF-2, (c) BF-4, (d) BF-5, and (e) BF-24. The time when the pyrolysis front passed the third TC and the remaining sample mass are indicated in $\mathrm{s}$ and \% respectively. 

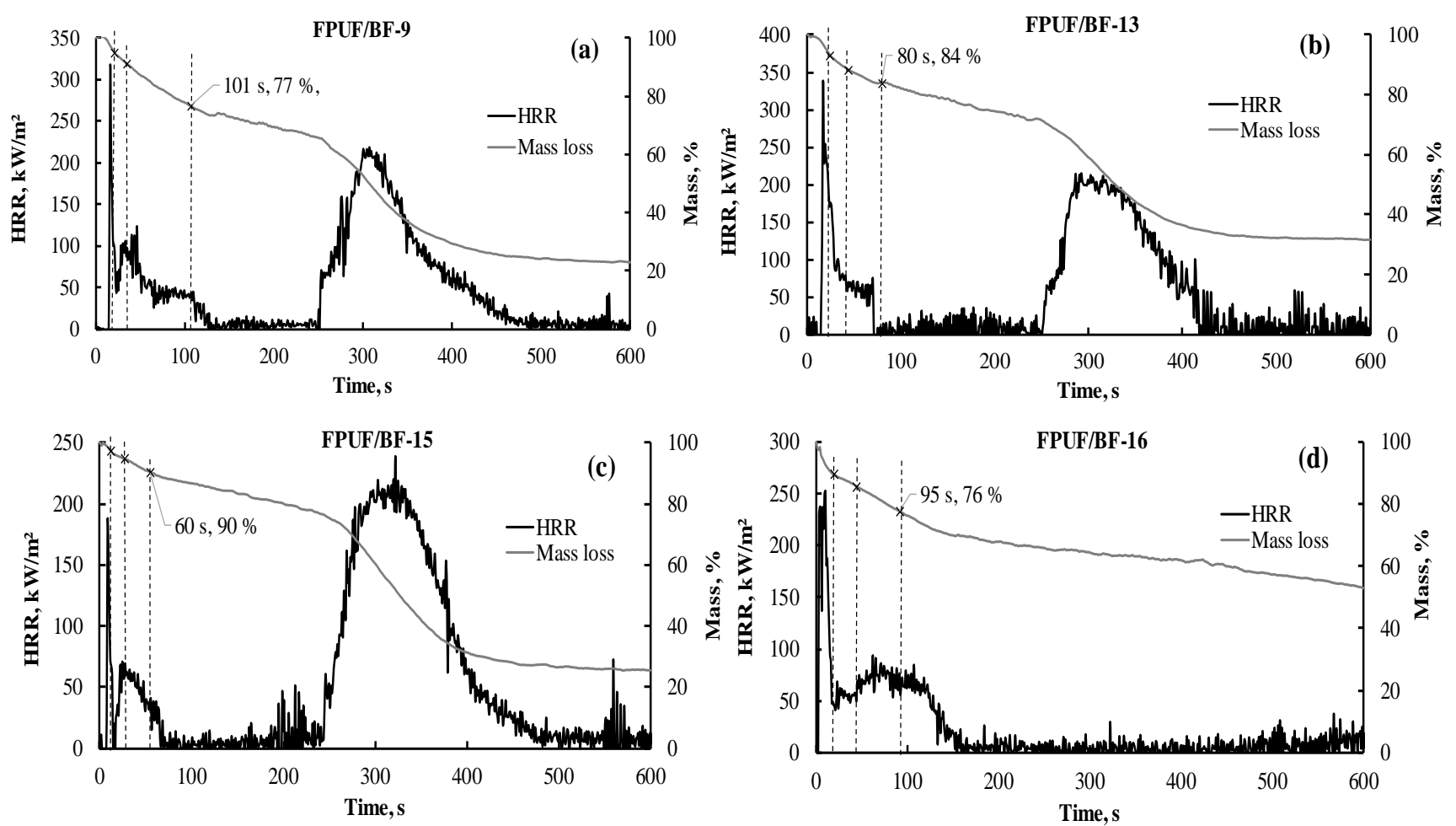

Fig. 9. Heat release rates and mass loss data for FPUF/BF composites with flat, permeable barriers showing flame extinction: (a) BF-9, (b) BF-13, (c) BF-15, and (d) BF-16. The time when the pyrolysis front passed the third TC and the remaining sample mass are indicated in $\mathrm{s}$ and $\%$ respectively. 

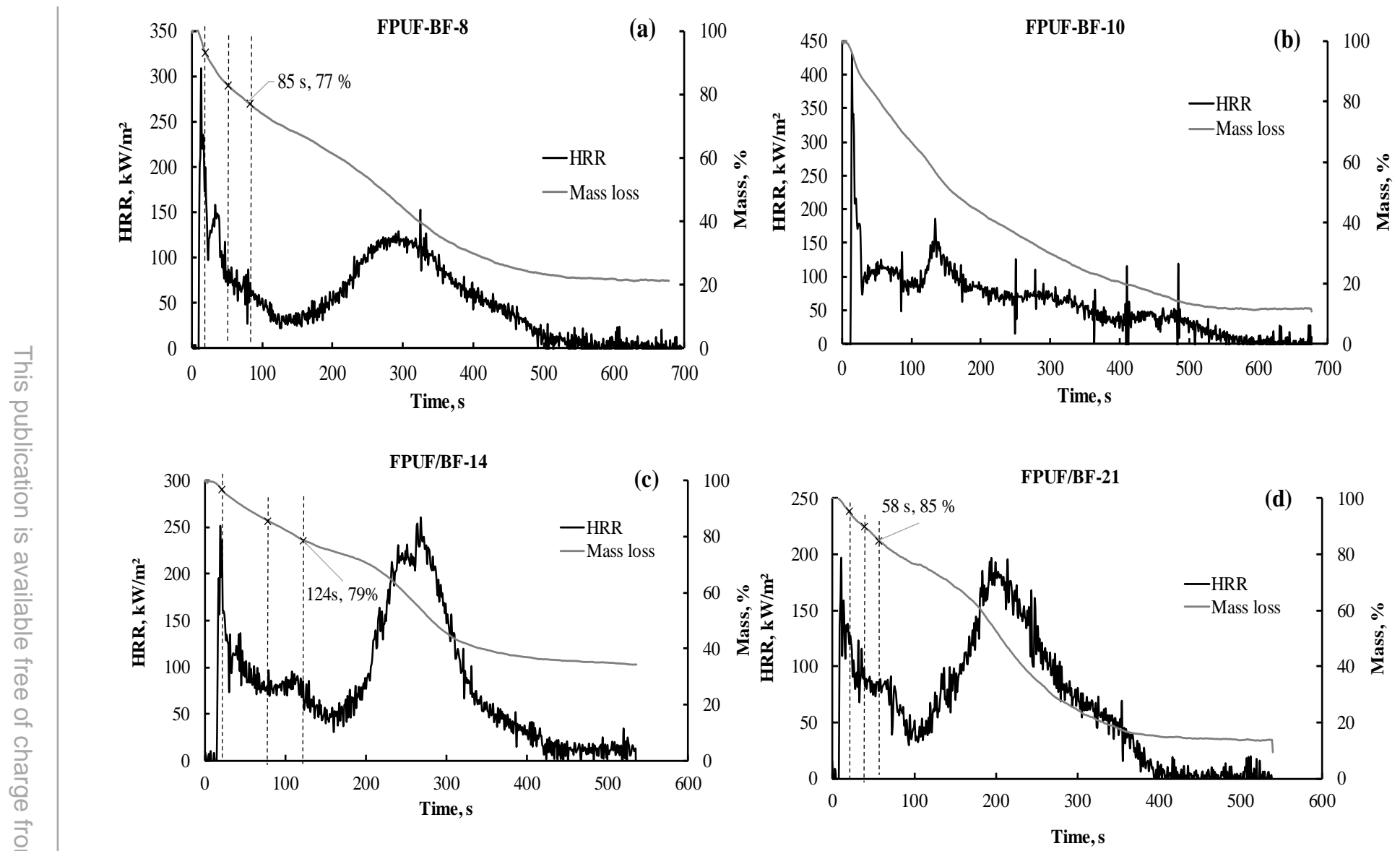

Fig. 10. Heat release rates and mass loss data for FPUF/BF composites with flat, permeable barriers showing no flame extinction: (a) BF-8, (b) BF-10, (c) BF-14, and (d) BF-21. The time when the pyrolysis front passed the third TC and the remaining sample mass are indicated in s and \% respectively. 

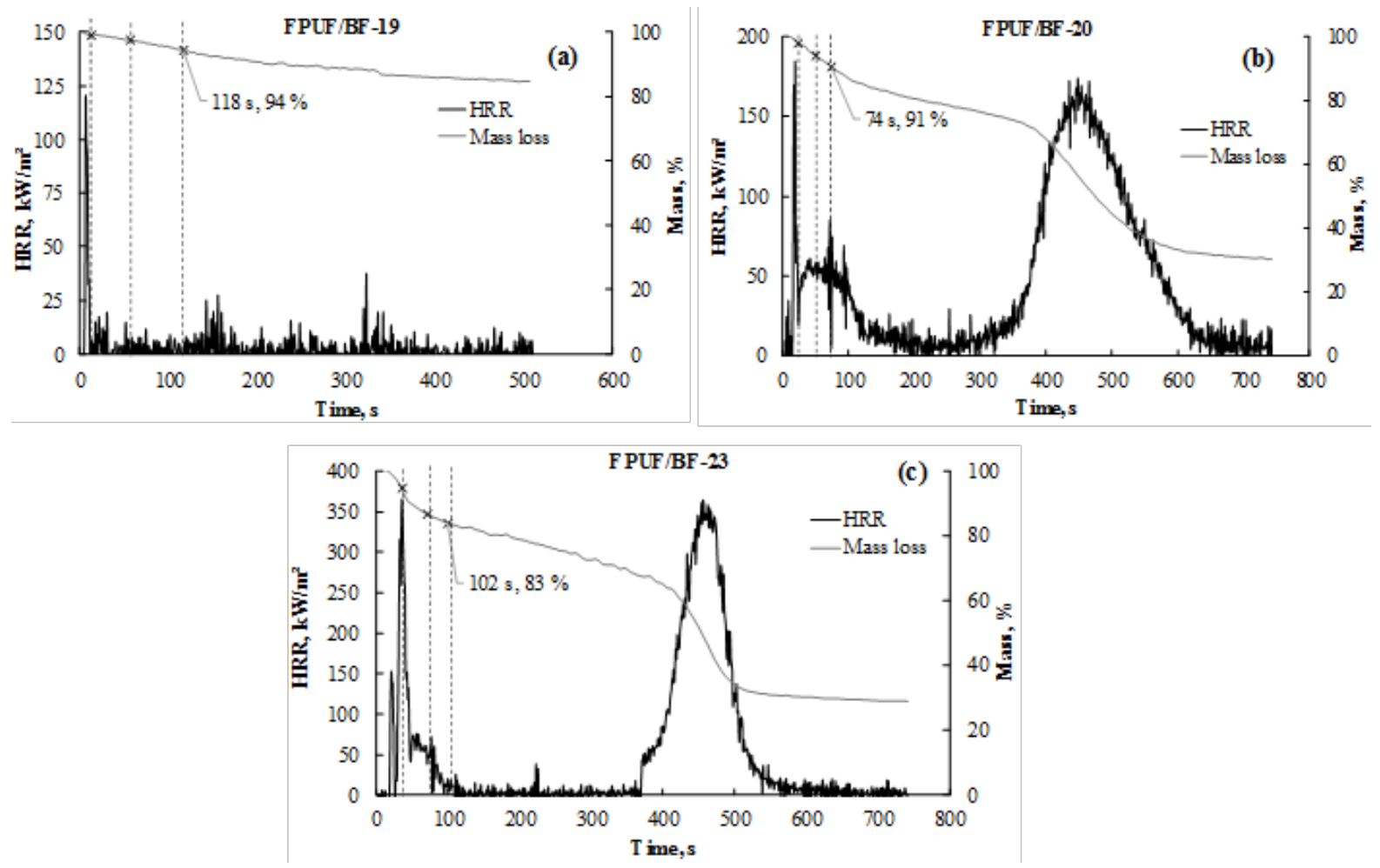

Fig. 11. Heat release and mass loss data for FPUF/BF composites with flat impermeable barriers: a) FPUF/BF-19, (b) FPUF/BF-20, and (c) FPUF/BF-23. The time when the pyrolysis front passed the third TC and the remaining sample mass are indicated in $\mathrm{s}$ and \% respectively.

The HRR curves for the composites incorporating BF-1, BF-13, BF-21, and BF-23 did not display three distinct maxima, however there were sharp initial maximum which occurred at times close to those when the foam pyrolysis fronts were located near the top TC location. During the periods immediately following the sharp peaks, the HRRs fell to lower levels and the FPUF was receding past the three TC locations. Close inspection of the HRR curves reveals shoulders during these periods that, while not providing clearly identifiable maxima, are consistent with the second peaks in the results discussed above. This suggests the burning behavior of these composites was similar and consistent with those where three distinct HRR peaks were identified.

Four of the sixteen composites, those with BF-10, BF-16, BF-19, and BF-24, did not display the three-stage burning described above. Each had a distinct and different burning behavior. The HRR curve for the composite with BF-10 in Fig. 10 has the distinctive initial peak indicative of flash burning of the barrier. This peak was followed by a long period of generally decreasing HRR that had multiple weak HRR maxima. The video for this test showed that the barrier fabric split open at around $150 \mathrm{~s}$ and exposed the underlying foam. Eventually the flames penetrated the barrier and burning was observed inside the composite. The nature of the structural failure of BF-10 and the burning of the FPUF below the remaining of BF-10 can be seen in Fig. 12 ((a)). A relatively sharp peak in the otherwise tapering HRR curve for FPUF/BF-10 can be seen in Fig. 10 (b) around 150 s. It is postulated that this complicated 
burning behavior involving penetration of the barrier fabric was responsible for the observed HRR profile.

Another example of a composite, FPUF/BF-21, that failed structurally due to the formation of cracks is shown in Fig. 12 (b). The resulting opening was much smaller than in BF-10 case, and does not seem to have significantly modified the burning behavior since the HRR curve in Fig. 10 (d) is consistent with the three-stage model.
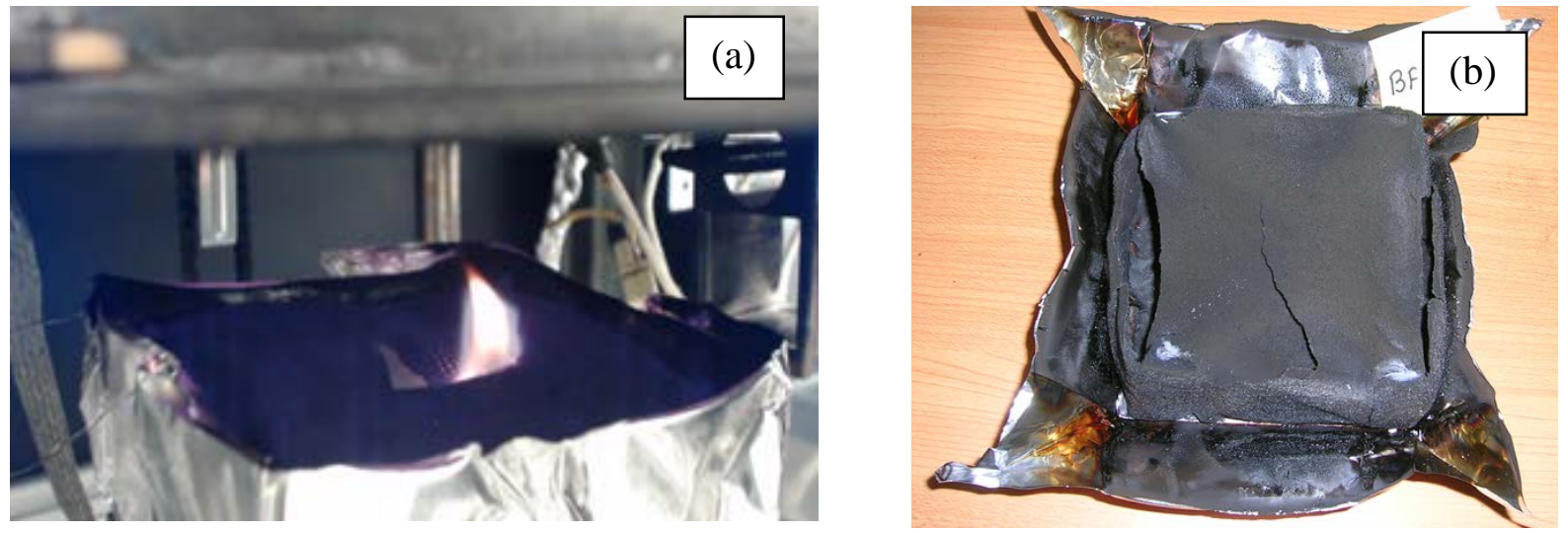

Fig. 12. Digital image of (a) FPUF/BF-10 and (b) FPUF/BF-21 composite showing opening of BF-10 char during burning and cracks in brittle char of BF-21 respectively.

The composite with BF-16 (Fig. 9 (d)) appears to have displayed the first two stages of the burning behavior, but then extinguished shortly after the FPUF fully collapsed into the sample pan. This conclusion is supported by the TC measurements as well as the large amount of mass remaining at the end of the experiment. Most of the polyol-derived material that accumulated in the aluminum pan after the initial collapse of FPUF (see Fig. 13) remained unburned as a mixture of liquid and char. The sample continued to lose mass at a relatively low rate after flame extinction.

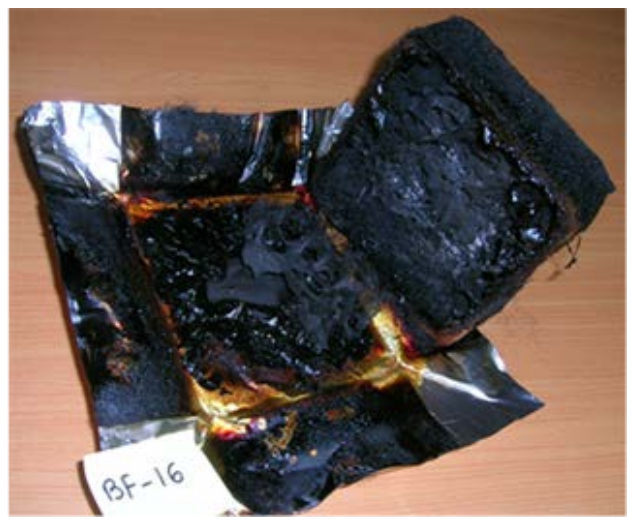

Fig. 13. Digital image showing a mixture of liquid material and char present at the end of a test for a FPUF/BF-16 composite. 
Close inspection of the HRR curve shows that there was still a very low level of measured HRR. Mass loss and heat release after flame extinction are consistent with smoldering and/or pyrolysis of the remaining polyol-derived material. Smoldering of the barrier was also visible during this time.

The HRR profile for the composite incorporating BF-19 (Fig. 11(a)) indicates that there was a flash ignition of the barrier $7 \mathrm{~s}$ after exposure to cone heating which resulted in the lowest corrected initial HRR peak observed for any of the composites (see Table 2). The flash flaming ignition was likely due to combustion of an organic coating that is typically applied to woven glass filament fabrics to improve water repellant and stain resistance properties. The flaming lasted only about $5 \mathrm{~s}$ before extinction took place (see Fig. 4). At the time of extinction, the pyrolysis front in the FPUF had not yet reached the TC located $5 \mathrm{~mm}$ below the original foam surface. Even though the spark ignition source was reapplied, no additional substantial flaming was observed even though the TC and mass measurements indicated that pyrolysis of the FPUF took place and that a polyol-derived liquid pool likely formed at the bottom of the sample pan. The mass loss at the end of the first peak was approximately $5 \%$ of the initial sample mass. This small mass loss during the brief initial burning of the composite suggests that it was largely associated with the burning of the organic coating on BF-19 and partial pyrolysis of the FPUF.

Fig. 14 (a) shows an example of the FPUF block appearance after removal of the barrier fabric when sample heating of a FPUF/BF-19 composite was terminated immediately following flame extinction. The total mass loss of this FPUF block was $0.3 \mathrm{~g}$, representing approximately $2 \%$ of the initial FPUF mass. It is evident that the FPUF was effectively protected by BF-19. As can be seen in Fig. 14 (b), the BF-19 shell remained structurally intact with no hole or crack formation during the long duration tests. The FPUF, however, did collapse and form a layer of pyrolyzate under the BF-19 shell. The average mass loss for composites with BF-19 was relatively low, $15.6 \% \pm 0.4 \%$, suggesting that some TDI-derived material was trapped along with material derived from polyol. This differs from the observations when FPUF was tested without a barrier.
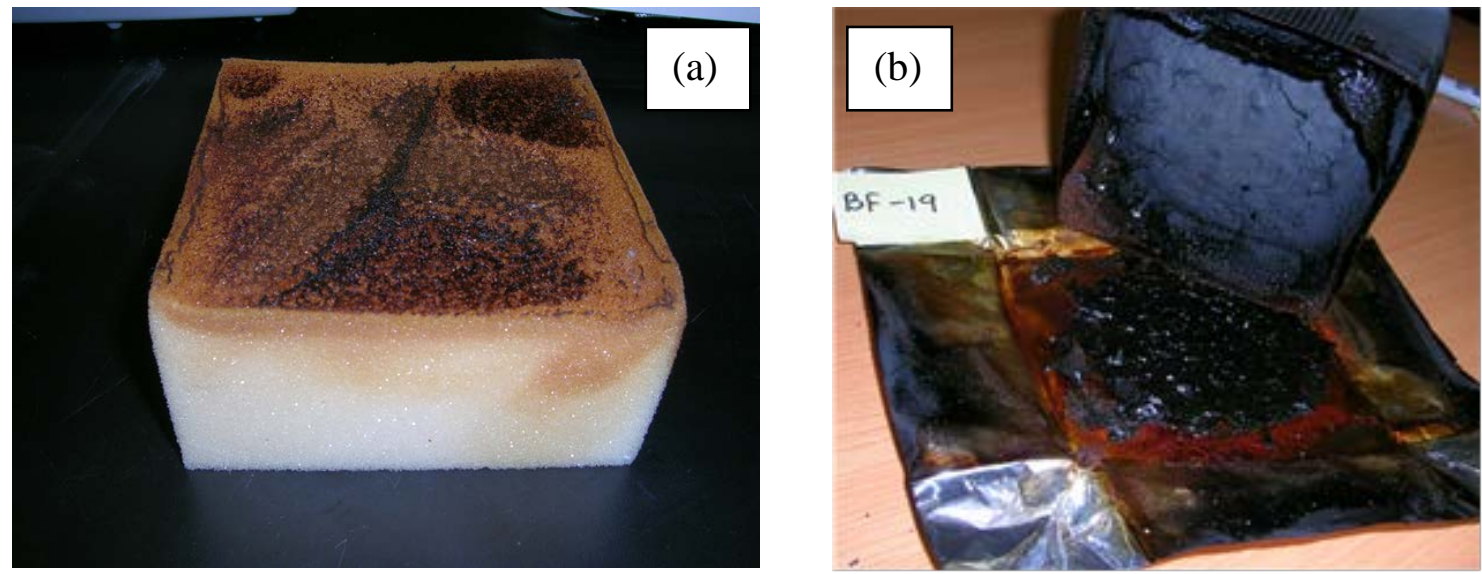

Fig. 14. Digital images of unburnt (a) FPUF for a test terminated immediately after the flaming phase and (b) liquid/char at the end of a full test of FPUF/BF-19 composites. 
The remaining composites that did not display the three-stage burning behavior were those including the nonwoven polyester batting, BF-24 (see Fig. 8 (e)). This suggest that flash burning of the polyester did not take place even though there was a rapid loss of sample mass immediately following exposure to the cone thermal radiation. The polyester batting melted and exposed the underlying FPUF to the radiant heat. Once the sample did begin to burn, the resulting HRR curve had a shape similar to those observed when FPUF was tested without a barrier (compare with Fig. 2 (a)), which displayed two distinct burning stages. For the FPUF, the two stages correspond to burning of TDI-derived and polyol-derived pyrolyzates. It is likely that the same is true for composite with BF-24. Comparison of the HRR curves shows that HRRs were considerably higher during both stages when the polyester was added to the FPUF. This suggests that even though polyester did not initially burn when exposed to cone heating, it did become involved and contributed to the overall HRR when flaming developed on the underlying FPUF.

The HRR and mass loss measurements were used to derive the set of experimental parameters summarized in Table 5 for FPUF and FPUF/BF composites. Parameters include the original sample mass, local values of HRR maxima (PHRR $\mathrm{PF}_{\mathrm{B}}$ PHHR $1, \mathrm{PHRR}_{2}$ ) based on the observed sequential burning behavior discussed earlier, average HRR integrated over the flaming period, total heat release obtained by integrating HRR over time, percentage of original sample mass lost over experiment, and the three FIGRA peak values (PFIGRA ${ }_{\mathrm{BF}}$, PFIGRA $_{1}$, and PFIGRA ) analogous to those for HRR. Note that the BFs are grouped in the same manner as in Fig. 9, Fig. 10, and Fig. 11.

For FPUF/BF composites with BF-9, BF-13, BF-15, BF-16, BF-19, BF-20, and BF-23 HRRs close to $0 \mathrm{~kW} / \mathrm{m}^{2}$ were observed during periods of continuing mass loss, i.e. pyrolysis and/or smoldering, during at least one of the repeated tests. This suggests that flame extinction occurred during these tests as confirmed by visual observation. Following flame extinction, the spark igniter was replaced above the sample and activated. The fractions of BF composites that showed flame extinction and those that reignited are provided in Table 4.

For composites with BF-15, BF-19, and BF-23, extinction occurred for all repeated tests (3/3.). For composites with BF-9 (2/4), BF-13 (3/4), BF-16 (2/4), and BF-20 (2/3), extinction occurred for a fraction of the repeated tests. The composites showing extinction included four of the eight with flat, permeable barriers and all three of the composites with flat impermeable barriers. In all but one of these composites, the exception being BF-19, the flame extinction occurred only after the collapse of the FPUF. This suggests that the pyrolysis rate or the flammability of the recently generated polyol-derived liquid may have been insufficient to support continued flaming.

With reapplication of the spark source, reignition of the polyol-derived pyrolyzate was observed in many of the tests following non-burning periods ranging from $100 \mathrm{~s}$ to $250 \mathrm{~s}$. In all cases, mass loss was observed during the non-flaming periods. This suggests continuing pyrolysis and/or smoldering. When reignition did take place, there were substantial increases in the mass loss rates. This suggests that the flames resulted in significant increases in the amount of heat reaching the liquid fuel in the bottom of the pan. Prior to reignition, there was no easily identified changes in sample mass loss rates. This observation suggests that 
continued heating of the liquid polyol-derived material generated pyrolyzate that was more easily ignited. The only composites which did not reignite in at least one repeated test were those with BF-19; BF-9, BF-13, BF-15, and BF-20 showed reignition during all repeated tests. Reignition failed for one of the repeated tests for composites with BF-16 and BF-23.

Substantial FPUF residue remained at the end of a test for composites with BF-16, BF-19, and BF-23 (Table 4). This suggests the occurrence of thermo-oxidative charring reactions in polyol-derived liquid (and perhaps some TDI-derived material) at the expense of pyrolysis. Charring of the liquid polyol suggests that slow heating of the fuels occurred in the presence of oxygen. This suggests, in turn, that these three barriers provided higher levels of protection for the FPUF than barriers where little or no residue remained, i.e., composites with BF-9, BF13, BF-15, and BF-20. The absence of reignition for all tests with BF-19 and some of those with BF-16 and BF-23 supports this conclusion. Taken together, the HRR, flame extinction and reignition behaviors indicate that the best performing composites included BF-19, followed by BF-16 and BF- 23.

Many of the BFs (BF-10, BF-13, BF-15, and BF-16) in composites where flame extinction was observed contain flame-retardant fibers or coatings that are known to operate in the gas phase. When released, such chemicals interfere with gas-phase combustion reactions and can inhibit or extinguish flames. Others BFs (BF-19, BF-20, and BF23) are classified as impermeable. Note that even if a barrier is impermeable, pyrolysis gases can flow between the outside edge of the barrier and aluminum pan since the FPUF is not covered by BF at the bottom. Properties such as gas permeability and thermal protective performance of the BFs can change as the BFs are heated. BFs with higher organic content can become more permeable to gas and more transparent to radiant heat as the organic fibers are consumed in the fire. Reignition of the FPUF/BF composites could be due to an increase in concentrations of pyrolysis gases at the spark igniter resulting from gradual increase in heat transfer and/or mass transfer through the barrier (i.e., mass transfer through the BF, higher pyrolysis rates of the polyol-derived liquid due to increased heat reaching the liquid), or changes in the flammability of the gas pyrolyzate formed as the polyol-derived liquid is heated. Based on the findings of this study, it was possible to determine the sensitivity of the observed reignition to such changes. 
Table 5. Cone calorimetry data for FPUF and FPUF/BF composites at $35 \mathrm{~kW} / \mathrm{m}^{2}$ heat flux. Uncertainties are reported as experimental standard deviations.

\begin{tabular}{|c|c|c|c|c|c|c|c|c|c|c|}
\hline \multirow{2}{*}{ Sample } & \multirow{2}{*}{$\begin{array}{l}\text { Initial } \\
\text { mass, g }\end{array}$} & \multicolumn{3}{|c|}{ PHRR, kW/m² } & \multirow{2}{*}{$\begin{array}{c}\text { Avg. HRR, } \\
\mathbf{k W} / \mathrm{m}^{2}\end{array}$} & \multirow{2}{*}{$\begin{array}{c}\text { THR, } \\
\mathbf{M J} / \mathbf{m}^{2}\end{array}$} & \multirow{2}{*}{$\begin{array}{l}\text { Mass lost, } \\
\%\end{array}$} & \multirow{2}{*}{$\begin{array}{l}\text { PFIGRA }_{B F} \\
\text { kW/m²-s }\end{array}$} & \multirow{2}{*}{$\begin{array}{l}\text { PFIGRA } \\
\text { kW/m²-s }\end{array}$} & \multirow{2}{*}{$\begin{array}{c}\text { PFIGRA } \\
\text { kW/m²-s }\end{array}$} \\
\hline & & PHRR $_{B F}$ & PHRR $_{1}$ & PHRR $_{2}$ & & & & & & \\
\hline $\begin{array}{l}\text { FPUF } \\
\text { (Marinite board } \\
\text { substrate) }\end{array}$ & $15.0 \pm 0.5$ & - & $253 \pm 20$ & $250 \pm 10$ & $219 \pm 19$ & $38.8 \pm 0.8$ & $100 \pm 0$ & - & $13 \pm 0.5$ & $2.80 \pm 0.31$ \\
\hline $\begin{array}{l}\text { FPUF } \\
\text { (Ceramic wool } \\
\text { substrate) }\end{array}$ & $15.0 \pm 0.5$ & - & $255 \pm 23$ & $481 \pm 49$ & $160 \pm 27$ & $39.1 \pm 0.3$ & $100 \pm 1$ & - & $10 \pm 1.4$ & $6.13 \pm 1.01$ \\
\hline & & & & & & & & & & \\
\hline $\begin{array}{l}\text { FPUF/BF-1 } \\
\text { FPUF/BF-2 }\end{array}$ & $\begin{array}{l}20.6 \pm 0.5 \\
27.7 \pm 0.7\end{array}$ & $\begin{array}{r}319 \pm 19 \\
427 \pm 138\end{array}$ & $\begin{array}{l}110 \pm 45 \\
157 \pm 20\end{array}$ & $\begin{array}{r}13 / \pm 45 \\
95 \pm 9\end{array}$ & $\frac{65 \pm 11}{50 \pm 5}$ & $\begin{array}{l}38.5 \pm 3.0 \\
37.4 \pm 5.6\end{array}$ & $\begin{array}{l}90 \pm 3 \\
86 \pm 8\end{array}$ & $\begin{array}{r}35 \pm 1 \\
126 \pm 20\end{array}$ & $\frac{5 \pm 3}{6 \pm 1}$ & $\frac{0.14 \pm 0.40}{0.38 \pm 0.10}$ \\
\hline FPUF/BF-4 & $25.4 \pm 0.2$ & $361 \pm 69$ & $113 \pm 4$ & $80 \pm 15$ & $50 \pm 4$ & $31.3 \pm 13.1$ & $77 \pm 20$ & $96 \pm 36$ & $1.7 \pm 0.1$ & $0.40 \pm 0.26$ \\
\hline FPUF/BF-5 & $27.8 \pm 0.9$ & $422 \pm 63$ & $115 \pm 25$ & $145 \pm 38$ & $70 \pm 9$ & $48.1 \pm 2.7$ & $92 \pm 2$ & $80 \pm 10$ & $1.6 \pm 0.7$ & $0.54 \pm 0.24$ \\
\hline FPUF/BF-24 & $22.4 \pm 0.4$ & - & $442 \pm 28$ & $791 \pm 43$ & $210 \pm 32$ & $50.4 \pm 0.6$ & $97 \pm 3$ & - & $18 \pm 4.0$ & $11.04 \pm 0.10$ \\
\hline FPUF/BF-9 & $24.0 \pm 0.1$ & $301 \pm 46$ & $98 \pm 16$ & $156 \pm 50$ & $83 \pm 20$ & $34.2 \pm 5.7$ & $79 \pm 2$ & $25 \pm 5$ & $2.1 \pm 0.9$ & $0.58 \pm 0.15$ \\
\hline FPUF/BF-13 & $26.8 \pm 0.2$ & $322 \pm 21$ & $65 \pm 12$ & $173 \pm 5$ & $119 \pm 60$ & $32.0 \pm 2.1$ & $67 \pm 1$ & $18 \pm 2$ & $1.0 \pm 0.6$ & $0.45 \pm 0.22$ \\
\hline FPUF/BF-15 & $21.2 \pm 0.2$ & $166 \pm 32$ & $59 \pm 2$ & $202 \pm 45$ & $125 \pm 28$ & $28.4 \pm 2.3$ & $78 \pm 10$ & $19 \pm 5$ & $1.5 \pm 0.2$ & $0.58 \pm 0.15$ \\
\hline FPUF/BF-16 & $26.1 \pm 0.1$ & $310 \pm 48$ & $87 \pm 15$ & $72 \pm 23$ & $45 \pm 11$ & $24.2 \pm 13.8$ & $61 \pm 6$ & $27 \pm 4$ & $1.3 \pm 0.3$ & $0.25 \pm 0.19$ \\
\hline FPUF/BF-8 & $24.7 \pm 0.9$ & $306 \pm 29$ & $142 \pm 11$ & $105 \pm 13$ & $51 \pm 6$ & $38.0 \pm 3.0$ & $79 \pm 3$ & $30 \pm 9$ & $3.5 \pm 0.4$ & $0.38 \pm 0.07$ \\
\hline FPUF/BF-10 & $21.5 \pm 0.6$ & $370 \pm 60$ & $103 \pm 6$ & $190 \pm 55$ & $66 \pm 19$ & $38.0 \pm 0.8$ & $87 \pm 2$ & $24 \pm 4$ & $1.2 \pm 0.2$ & $1.20 \pm 0.37$ \\
\hline FPUF/BF-14 & $29.2 \pm 0.1$ & $257 \pm 19$ & $86 \pm 2$ & $245 \pm 74$ & $80 \pm 18$ & $41.7 \pm 1.9$ & $71 \pm 1$ & $14 \pm 1$ & $0.7 \pm 0.1$ & $1.00 \pm 0.37$ \\
\hline FPUF/BF-21 & $17.6 \pm 0.2$ & $199 \pm 49$ & $88 \pm 14$ & $189 \pm 14$ & $77 \pm 11$ & $35.4 \pm 1.6$ & $87 \pm 2$ & $19 \pm 11$ & $1.0 \pm 0.2$ & $0.97 \pm 0.18$ \\
\hline FPUF/BF-19 & $25.8 \pm 0.2$ & $102 \pm 10$ & - & - & $4 \pm 3$ & $1.5 \pm 1.0$ & $16 \pm 1$ & $13 \pm 1$ & - & - \\
\hline FPUF/BF-20 & $25.4 \pm 0.2$ & $209 \pm 37$ & $56 \pm 3$ & $259 \pm 122$ & $53 \pm 13$ & $36.0 \pm 1.7$ & $72 \pm 1$ & $13 \pm 4$ & $0.9 \pm 0.2$ & $0.70 \pm 0.35$ \\
\hline FPUF/BF-23 & $36.2 \pm 0.3$ & $373 \pm 13$ & $66 \pm 15$ & $416 \pm 95$ & $69 \pm 21$ & $45.0 \pm 7.4$ & $69 \pm 27$ & $11 \pm 1$ & $0.9 \pm 0.2$ & $1.17 \pm 0.38$ \\
\hline
\end{tabular}




\subsection{Decoupling roles of active and passive effects on flame extinction}

For several of the tests, the burnt BF "cage" was strong enough to handle and even reuse. This provided a unique opportunity to obtain insights into the role of flame retardants in reducing composite flammability. Only BFs containing glass fiber/filaments, BF-13, BF-15, and BF16, were considered for these experiments. The presence of glass filaments helped maintain the structural integrity of the BF shell, making it convenient to reuse the shell. The contributions of active and passive mechanisms for protecting the underlying FPUF were assessed by comparing HRR profiles of FPUF/BF composites incorporating pristine BFs containing active, gas-phase flame-retardant chemicals with FPUF/BF composites prepared with shells recovered from earlier experiments. It was assumed that any added flame retardant and volatile components in the BFs were consumed during the initial testing. Therefore, the recovered BF shell should only contain thermally stable components. This hypothesis was supported by the observation that no flash ignition occurred for these three previously used BFs when tested alone in the cone calorimeter.

The comparison of HRR profiles for FPUF/BF composites with pristine and previously tested BF shells is shown in Fig. 15. The burning behavior of each composite changed when the pristine BF was replaced with the previously tested BF. There were sharp HRR peaks immediately following ignition for each pristine BF. These were likely associated with flash burning of the exposed BF (as already described). These peaks were not evident when previously tested BFs were used, which suggests that any organic volatile material and flame retardants present in the BF were removed during initial testing. It is also evident that the HRR associated with the burning of the TDI-derived component of the composites was generally reduced compared to the cases with the previously tested barriers. This suggests that the flame retardants inhibited, but did not suppress, burning during these periods.

The BF-13, BF-15, and BF-16 composites all showed flame extinction in a majority of tests (see Table 4) after the TDI-derived pyrolylzate was consumed. In the cases with pristine BF13 and BF-15, the FPUF re-ignited after a delay period following reapplication of the spark igniter for each test in which flame extinction occurred. It is considered likely that any organics and flame-retardant chemicals in the barriers were depleted by this time, and ignition was due to ignition of polyol-derived pyrolyzate. Interestingly, neither of these two composite types showed flame extinction when the previously tested barriers were used. This suggests that FRs in these barriers played a role in the flame extinction behavior for these two barriers.

In the example shown in Fig. 15, the FPUF/BF-16 composite did not reignite as the liquid polyol-derived material accumulated in the aluminum pan, but did reignite in the remaining two tests in which flame extinction was observed. Flame extinction was also observed in the test with the previously tested barrier. This result suggests that this previously tested BF shell, which is assumed to be acting in a passive manner, is more effective than the previously tested shells for BF-13 and BF-15.

It is of interest to compare the HRR temporal behaviors for the three composite types with those for FPUF shown in Fig. 2 and summarized in Table 5. Values of $\mathrm{PHRR}_{1}$ are roughly $100 \mathrm{~kW} / \mathrm{m}^{2}$ for each of the composites with previously tested BFs, while the corresponding 
value for unprotected FPUF is $255 \mathrm{~kW} / \mathrm{m}^{2}$. This represents roughly a $60 \%$ reduction for each $\mathrm{BF}$.
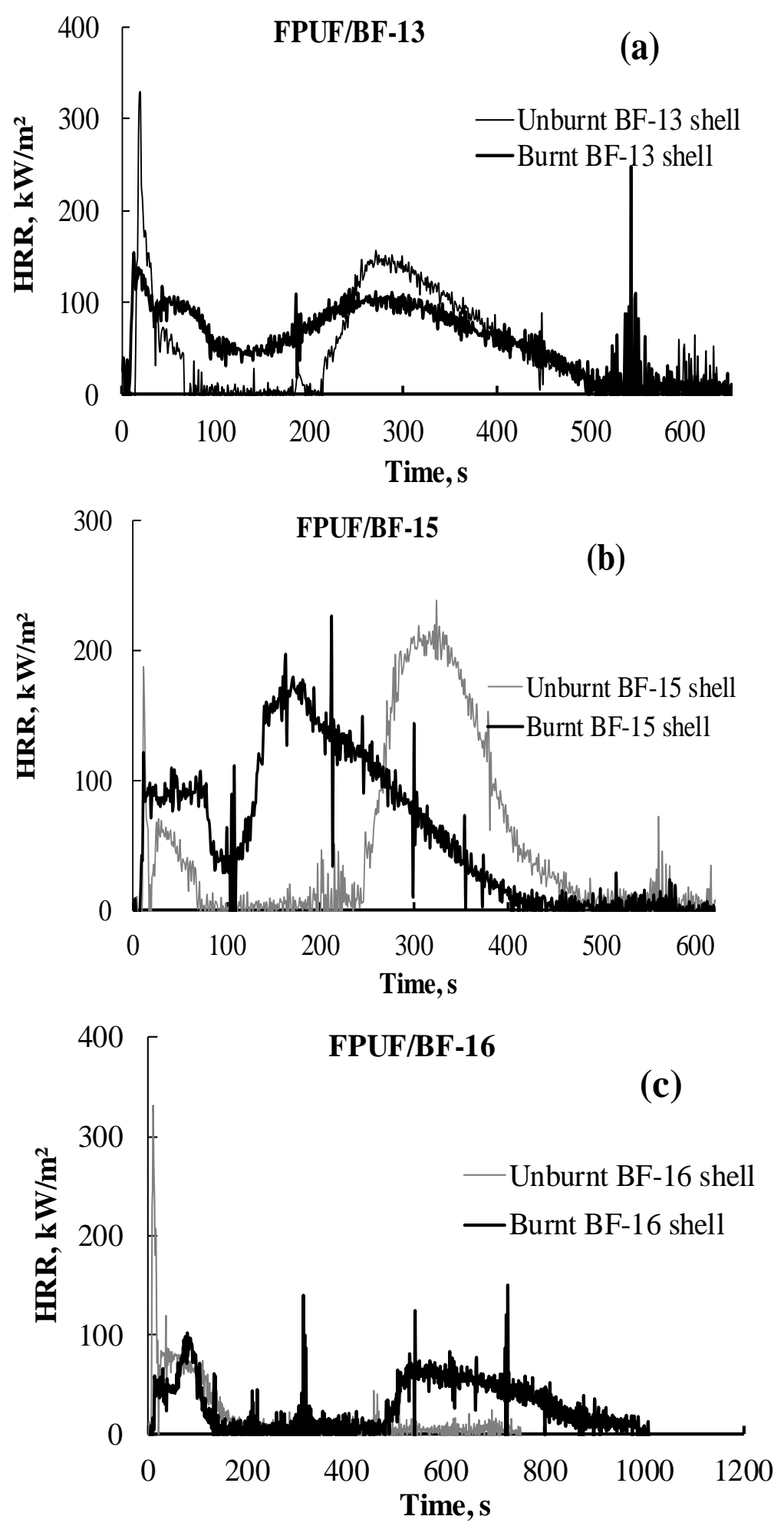

Fig. 15. Comparison of HRR profiles (corrected for time response effects) with unburnt pristine and burnt BF shell for (a) FPUF/BF-13, (b) FPUF/BF-15, and (c) FPYF/BF-16 composites. 
Values of PHRR 2 vary somewhat more, $150 \mathrm{~kW} / \mathrm{m}^{2}$ with BF-13, $200 \mathrm{~kW} / \mathrm{m}^{2}$ with BF-15, and $50 \mathrm{~kW} / \mathrm{m}^{2}$ with BF-16. The corresponding value for FPUF was $480 \mathrm{~kW} / \mathrm{m}^{2}$. The reductions in $\mathrm{PHHR}_{2}$ range from $60 \%$ to $90 \%$. In general for this limited set of experiments, the reductions seem larger for the peaks associated with the burning of the polyol-derived liquid and previously burned BF-16 appears to once again be the most effective of the three.

\subsection{Ranking of Barrier Fabric Effectiveness}

The primary purpose of a $\mathrm{BF}$ is to limit the cushioning material involvement in a fire by preventing and/or significantly delaying the combustion of core materials, lowering the heat release rate, reducing the rate of flame spread, and/or extinguishing the flames. Therefore, in order to assess the effectiveness of a BF, modifications to the burning behavior of FPUF should be considered. Indicators for reaction-to-fire based on cone measurements such as the PHRR, THR, Avg. HRR, and mass loss (ML) are often used for comparison or ranking of materials. Most often PHRR is used as the characteristic measure in foam/fabric composites [62]. However, as discussed above, the FPUF/BF composites studied here typically have HRR curves consistent with three-stage burning. The choice of the first peak, PHRR $\mathrm{BF}_{\mathrm{B}}$, which is usually due to flash-flaming burning of the BFs and has the highest value, may not be appropriate for ranking BF effectiveness. Moreover, as pointed out by Forsten [25] and Olhemiller [26], the PHRR of FPUF/fabric composites from the cone calorimeter test does not correlate well with the PHRR measured for actual upholstered furniture.

The changes in $\mathrm{PHRR}_{1}$ and $\mathrm{PHRR}_{2}$, Avg. HRR, and THR of the FPUF in the presence of the various BFs are shown in Fig. 16 (a) - Fig. 16 (c) plotted as percentage differences between the values for FPUF/BF composite normalized by the FPUF value as a function of BF number. Negative values indicate that the inclusion of BFs resulted in improved flammability behavior while positive values indicate poorer flammability performance. Hatched bars indicate samples displaying flame extinction behavior in one or more tests. It is considered likely that the PHRR 2 due to burning of polyol-derived liquid would not have occurred if the spark igniter was not re-inserted. In such cases the value of the hatched bars would have been $-100 \%$, with the negative sign indicating a zero value for $\mathrm{PHRR}_{2}$.

Table 6. Classification of BF effectiveness based on flame extinction behavior.

\begin{tabular}{|c|c|c|c|}
\hline Class & & Burning behavior & $\begin{array}{l}\text { BF component in FPUF/BF } \\
\text { composite }\end{array}$ \\
\hline 1 & 舟 & $\begin{array}{l}\text { Flame extinction, no re- } \\
\text { ignition }\end{array}$ & BF-16, BF-19 \\
\hline 2 & 氙 & Flame extinction, re-ignition & BF-9, BF-13, BF-15, BF-20, BF-23 \\
\hline 3 & & No flame extinction & $\begin{array}{l}\text { BF-1, BF-2, BF-4, BF-5, BF-8, BF-10, BF- } \\
\text { 14, BF-21, BF-24 }\end{array}$ \\
\hline
\end{tabular}


Flame extinction during cone testing is a possible indicator of better barrier effectiveness as compared to composites in which flame extinction was not observed. Whether or not a composite reignited following flame extinction provides further differentiation. This suggests a three-level rating system for barrier effectiveness based on flame extinction: 1) flame extinction with no re-ignition, 2) flame extinction with re-ignition, and 3) no flame extinction. For composites where mixed results were observed, conclusions were based on the behavior most often observed. Table $\mathbf{6}$ shows the barriers considered in this study ranked in this manner with barrier effectiveness decreasing and fire hazard increasing from Class 1 to Class 3.

It can be seen from Fig. 16 (a) that, with the exception of BF-24, both PHRR 1 and $\mathrm{PHRR}_{2}$ were significantly reduced in the presence of a $\mathrm{BF}$, as compared to corresponding values for bare FPUF. Maximum reductions in PHRR ${ }_{1}$ were observed for composites with BFs containing gas-phase active FRs or BFs with low permeability made from highly fire-resistant fibers. However, as discussed earlier, flame retardants are expected to be consumed in the early phases of sample burning, and the burning of polyol-derived liquid should have taken place after any flame retardants were consumed. Moreover, burning of the polyol-derived liquid was more intense compared to burning of TDI-derived species and resulted in higher HRR values $\left(481 \mathrm{~kW} / \mathrm{m}^{2} \pm 49 \mathrm{~kW} / \mathrm{m}^{2}\right)$ for bare FPUF. It was also observed that the range of values was wider for $\mathrm{PHRR}_{2}$. For these reasons, it is concluded that $\mathrm{PHRR}_{2}$ values are more appropriate for assessing BF effectiveness than PHRR 1 .

The reduction in $\mathrm{PHRR}_{2}$ was likely due to the reduced heating rate of the polyol-derived material in the presence of the BF and to any incomplete combustion of FPUF residue. For effective BFs, the PHRR 2 was significantly delayed and had reduced intensity as compared to bare FPUF. Excluding BF-24, PHRR 2 reductions ranged from $-14 \%$ to $-100 \%$ and showed substantial variations between BFs. BF-19 provided the best thermal protective performance with the peak due to polyol-derived liquid burning being completely absent. For FPUF/BF24, the PHRR 2 increased by more than half, suggesting that a large fraction of the polyester became involved during the involvement of the polyol-derived liquid. This behavior would likely result in an increased fire hazard. 

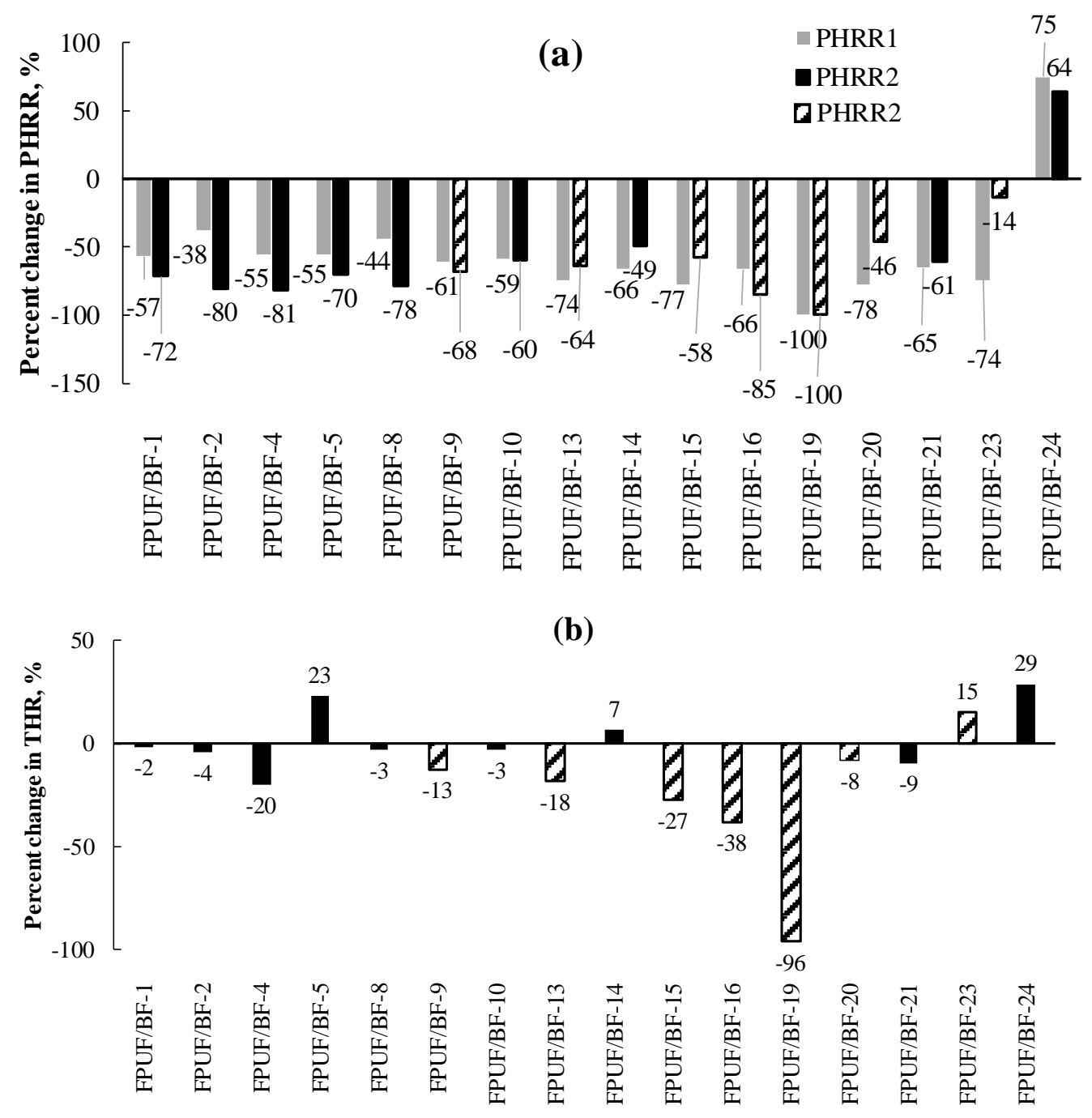

(c)

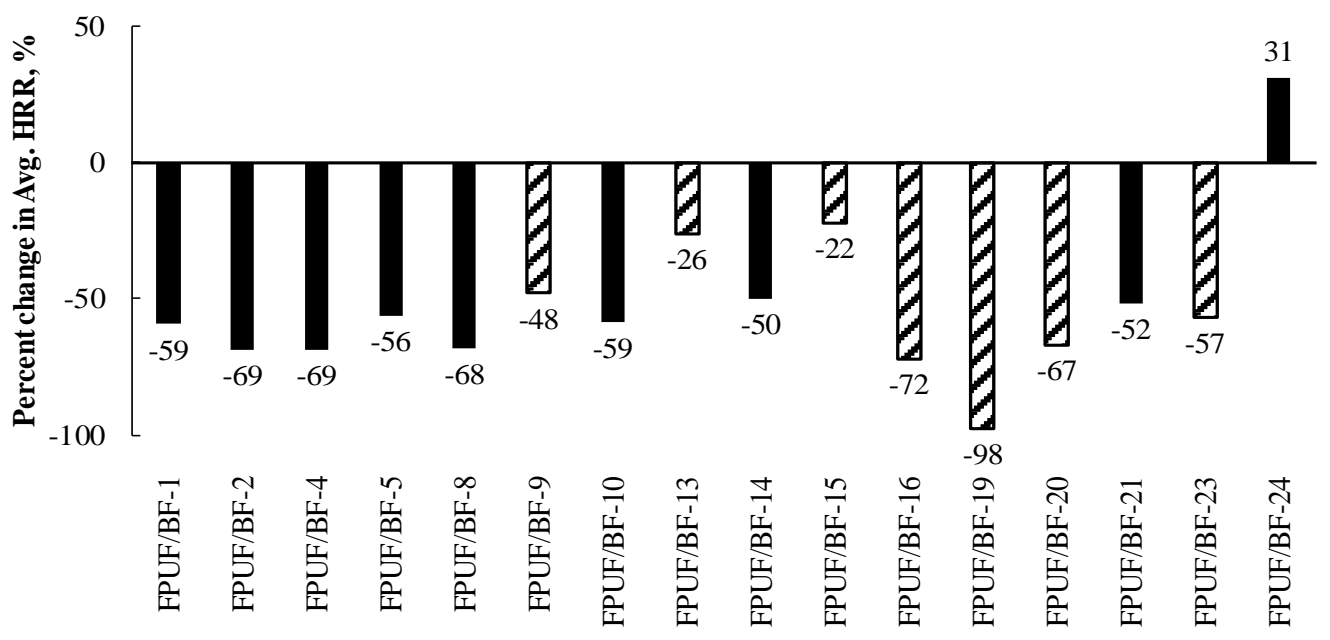

Fig. 16. Changes in (a) $\mathrm{PHRR}_{1}$ and $\mathrm{PHRR}_{2}$, (b) THR, and (c) Avg. HRR for FPUF composites as compared to FPUF alone tested under $35 \mathrm{~kW} / \mathrm{m}^{2}$ heat flux in the cone calorimeter. 
The THR is related to the total amount of fuel present and the fraction consumed. Most of the BFs considered here are expected to contain flammable components that could contribute to the THR. Comparison of data in Fig. 16 (b) reveals that FPUF/BF composites with BF-5, BF14, BF-23, and BF-24 had higher values of THR, as compared to FPUF alone. Many of the remaining BFs resulted in minimal decreases. Only composites with BF-4, BF-15, BF-16, and BF-19 resulted in reductions of $20 \%$ or more as compared to FPUF alone. While this parameter seems to identify particularly effective BFs, it does not seem appropriate for differentiating between a wide variety of BFs.

Fig. 16 (c) shows variations in Avg. HRR for FPUF/BF composites taken over the duration of flamming combustion. All of the BFs, with the exception of BF-24, showed significant reductions in this parameter with values in the range of $50 \%$ to $98 \%$, as compared to bare FPUF. Average heat release rate is often considered as a suitable parameter for comparing burning behaviours of foam/fabric composites [22]. However, for low-flammability, selfextinguishing systems such as those considered in this study, Avg. HRR may be inappropirate because the samples continued to lose mass during periods of non flaming prior to re-ignition of the sample. It is also evident from Fig. 16 (c) that many of the tested BFs have Avg. HRR values decreasing by almost $60 \%$. The narrow range of the variations also suggests that this parameter may not be effective in differentiating between a wide range of BFs.

Based on the above discussion of this limited data set we conclude that $\mathrm{PHRR}_{2}$ is the most appropriate of these four HRR-based parameters for ranking the lab-scale thermal protective performance of BFs. Fig. 17 shows the ranking of BFs based on this parameter. The value for unprotected FPUF is included for comparison purposes. Best performing BFs in terms of limiting $\mathrm{PHRR}_{2}$ are on the extreme left of the $\mathrm{x}$-axis with less protective BFs to the right.

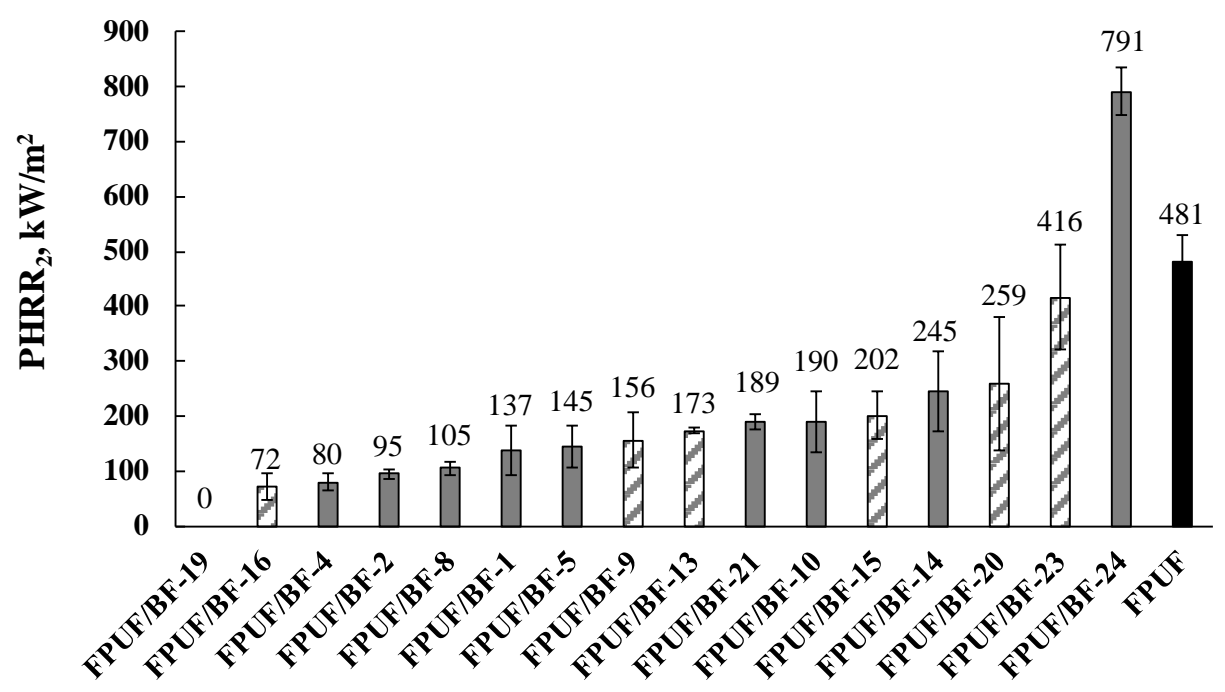

Fig. 17. Ranking of barrier fabrics (BFs) using $\mathrm{PHRR}_{2}$ of the FPUF/BF composites.

The values vary significantly with barrier type and seem to fall into three distinct groups with low, medium, and high $\mathrm{PHRR}_{2}$ having approximate ranges of $0 \mathrm{~kW} / \mathrm{m}^{2}$ to $125 \mathrm{~kW} / \mathrm{m}^{2}$, > 125 
$\mathrm{kW} / \mathrm{m}^{2}$ to $225 \mathrm{~kW} / \mathrm{m}^{2}$, and $>225 \mathrm{~kW} / \mathrm{m}^{2}$. These HRR ranges are used as the basis for the three-level classification system of barrier effectiveness shown in Table 7.

Table 7. Classification of BF effectiveness based on $\mathrm{PHRR}_{2}$ values.

\begin{tabular}{|c|c|c|c|}
\hline Class & & PHRR2, W/m² $^{2}$ & BF component in FPUF/BF composite \\
\hline 1 & ปี & $<125$ & BF-2, BF-4, BF-8, BF-16, BF-19 \\
\hline 2 & 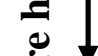 & 125 to 225 & BF-1, BF-5, BF-9, BF-10, BF-13, BF-15, BF-21 \\
\hline 3 & 江 & $>225$ & BF 14, BF-20, BF-23, BF-24 \\
\hline
\end{tabular}

Reductions in HRR provide a powerful approach for reducing the fire hazard of real systems. While not considered as frequently, delaying the onset of potentially dangerous HRRs can also reduce the fire hazard by providing longer periods for detection, fire-fighting, and egress. The FIGRA parameter incorporating the joint effects of decreasing HRRs and increasing the time required to reach dangerous HRRs was introduced above. While the exact relationship between FIGRA and fire hazard is generally not quantified, a strong correlation can be expected. On this basis the FIGRA concept was considered for classifying the results of the current cone calorimeter study. Table 5 includes values PFIGRA BF $_{\text {PFIGRA }}$, and PFIGRA 2 defined by analogy with the corresponding HRR peaks. For the same reasons discussed above for $\mathrm{PHRR}_{2}$, values of PFIGRA 2 were chosen to rank BF effectiveness.

Fig. 18 shows PFIGRA 2 values for the BFs ordered from lowest to highest along with the corresponding value for FPUF without a barrier. The numerical range of PFIGRA 2 values was wider than for the corresponding range of $\mathrm{PHRR}_{2}$ values and should provide more differentiation between BFs. As found for rankings based on PHRR $2, B F-19$ and BF-16 provide the best PFIGRA2 performance while BF-23 and BF-24 fall at the opposite extreme along with BF-10. Comparison with Fig. 17 shows that there is some reordering of BF effectiveness between these extremes when characterized in terms of $\mathrm{PHRR}_{2}$ and PFIGRA2. 


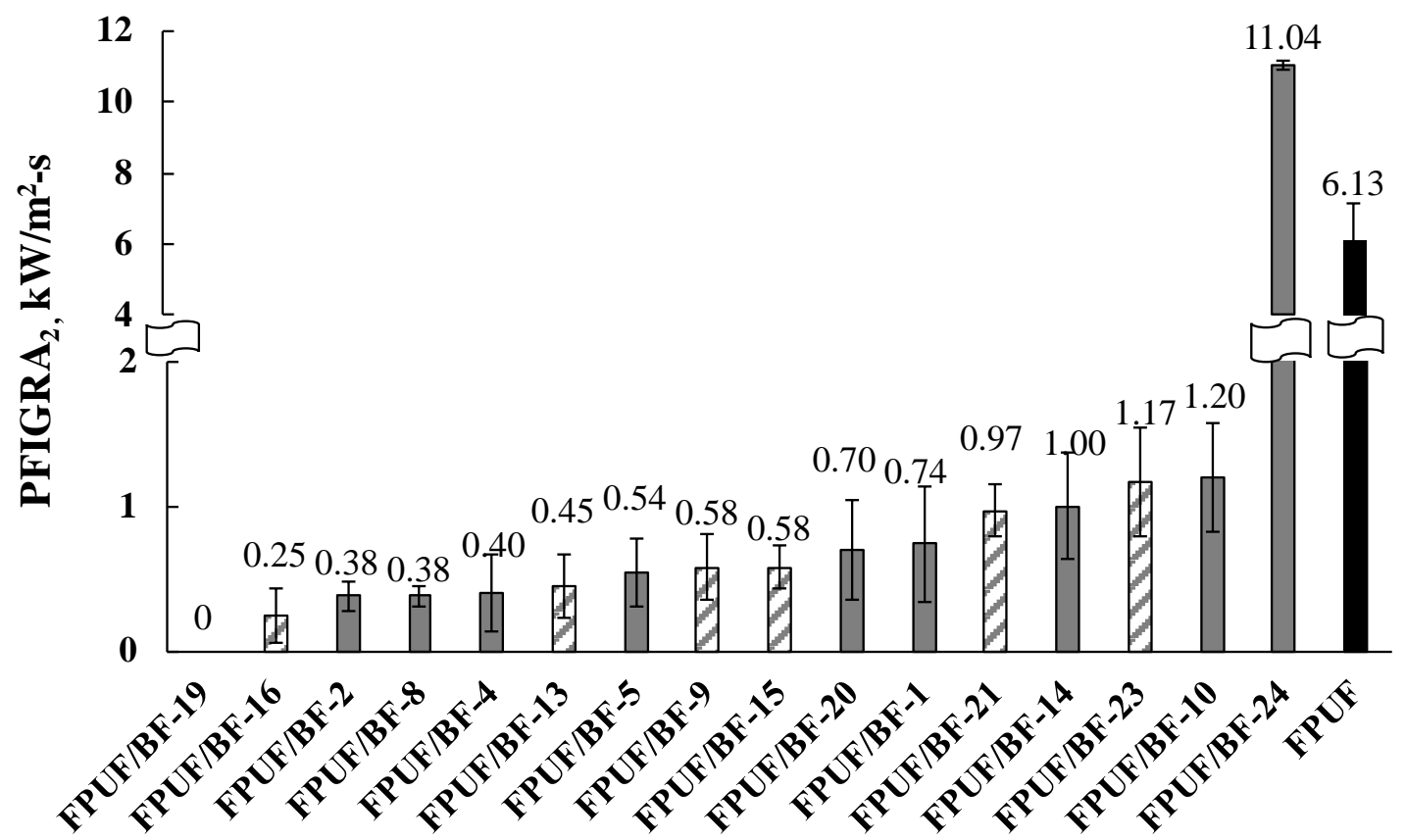

Fig. 18. Ranking of barrier fabrics (BFs) using PFIGRA 2 of the FPUF/BF composites.

Similar to the results for $\mathrm{PHRR}_{2}$, the BF results seem to naturally group into three ranges of $0 \mathrm{~kW} / \mathrm{m}^{2}$ - s to $0.5 \mathrm{~kW} / \mathrm{m}^{2}$-s, $>0.5 \mathrm{~kW} / \mathrm{m}^{2}$-s to $0.85 \mathrm{~kW} / \mathrm{m}^{2}$-s, and $>0.85 \mathrm{~kW} / \mathrm{m}^{2}$-s. The barrier fabrics classified using these rages are shown in Table 8.

Table 8. Classification of BFs based on PFIGRA 2 values.

\begin{tabular}{|c|c|c|c|}
\hline Class & \multirow{4}{*}{ 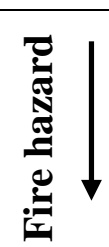 } & PFIGRA2, $\mathrm{kW} / \mathrm{m}^{2}$-s & BF component in FPUF/BF composite \\
\hline 1 & & $<0.5$ & BF-2, BF-4, BF-8, BF-13, BF-16, BF-19 \\
\hline 2 & & 0.5 to 0.85 & BF-1, BF-5, BF-9, BF-15, BF-20, \\
\hline 3 & & $>0.85$ & BF-10, BF-14, BF-21, BF-23, BF-24 \\
\hline
\end{tabular}

The ranges chosen to rank BFs in terms of their $\mathrm{PHRR}_{2}$ or PFIGRA ${ }_{2}$ are expected to vary with sample configuration and cone calorimeter settings. The experimental values are likely to depend on experimental conditions and the ranges used in Table $\mathbf{7}$ and Table 8, therefore, should not be considered as universal.

The three BF classification schemes provide different rankings. The BFs which fall into the same class for each are bolded in Table 6, Table 7, and Table 8. It is likely significant that all three classifications identify BF-16 and BF-19 as being particularly effective, while BF-24 is identified as being very poor. However, the remaining barriers shift between classes depending on the ranking basis.

Different classification results between the approach based on extinction behavior and those based on the HRR measurements are not surprising. After all, the protective performance of BFs depends on a variety of BF attributes. For example, BF- 2, BF-4 and BF-8 that appear in Class 1 in Table 7 and Table 8 are classified as non-self-extinguishing (Class 3) BFs in Table 
6. While these BFs are very effective in producing thermally protective char that is instrumental in significantly lowering the $\mathrm{PHRR}_{2}$, they do not exhibit flame extinction. Direct comparison between the classification results based on $\mathrm{PHRR}_{2}$ and $\mathrm{PFIGRA}_{2}$ shows good agreement between the classes with only BF- 13 and BF-20 moving up one class when PFIGRA $_{2}$ is considered and BF-10 and BF-21 moving down one class. These shifts in class are consistent with the observed temporal HRR profiles. Although, BF-13 and BF-20 had high $\mathrm{PHRR}_{2}$, the time at which the peak occurred was significantly delayed, thus lowering the PFIGRA $_{2}$ value. Conversely, BF- 10 and BF-21 have lower PHRR $_{2}$ but since the BFs cracked open and the peak occurred much earlier in the tests, resulting in higher PFIGRA $\mathrm{A}_{2}$ values.

Each of the classification schemes is based on a cone calorimeter response determined by BF properties expected to play dominant roles in BF effectiveness when used in full-scale RUF. The variations in BF classifications between the three approaches suggest that each cone calorimeter response is sensitive to different combinations of BF properties and/or cone calorimeter sample configuration. Additional work is required to determine which, if any, of the classification schemes will best correlate with BF effectiveness when employed in fullscale RUF.

\section{Conclusions}

The burning behavior of small-scale mock-ups of FPUF and a range of BFs in a cone calorimeter have been characterized. In addition to BF properties, it has been demonstrated that the burning behaviors of the FPUF/BF composites are sensitive to a wide range of experimental parameters including the sample configuration, heat losses to the underlying substrate, and the two-stage pyrolysis behavior of the FPUF.

In earlier work we identified four BF properties; burning behavior, permeability, thermal protection of underlying material, and physical integrity; as being determinants of $\mathrm{BF}$ effectiveness [6, 8]. Various experimental approaches were used to characterize these BF properties. The current results provide additional support for the important role of these BF properties in protecting underlying soft cushioning material. The results have also revealed that added BF flame retardants which act in the gas phase can also inhibit burning in cone calorimeter experiments. This suggests that flame retardancy should be included as a fifth determiner of BF effectiveness. It must, however, be recognized that the use of flame retardants is currently being strongly discouraged or banned due to concerns related to human health and environmental effects [63, 64].

The crucial role played by two-stage burning of FPUF in the cone calorimeter was demonstrated by experiments on bare FPUF where two distinct HRR peaks were observed. The first corresponded to burning of pyrolysis gases derived from the TDI component as the foam collapsed and the second by pyrolysis of a liquid layer formed in the bottom of the test pan primarily by the polyol component. TC measurements within the foam confirmed its rapid collapse during the initial burning stage. Variations in second-stage $\mathrm{PHRR}_{2}$ with changes in the substrate underlying the sample test pan revealed the sensitivity of the pyrolysis rate of the liquid to heat losses to the surroundings. The more insulating substrate was used for BF testing in order to provide a more severe fire condition. 
Cone calorimeter tests involving upholstery fabrics, BFs, and FPUF often result in very rapid changes in HRR. Cone calorimeters are known to have finite time responses that can alter HRR during rapid transients. It was shown that such effects were important in many of the tests performed during this study. This was particularly true when flash burning of the BFs occurred. Initial peaks in HRR (PHRR $\mathrm{BF}$ ) curves were underestimated by $40 \%$ to $270 \%$ and the times to peak $\left(\mathrm{TTP}_{\mathrm{BF}}\right)$ were overestimated by $4 \mathrm{~s}$ to $14 \mathrm{~s}$, depending on the burning behavior of the BF. These findings demonstrate the need for time-response corrections in cone calorimeter experiments involving such materials.

Cone calorimetry HRR curves for most of the FPUF/BF composites studied here displayed three peaks attributable to sequential burning of the barrier $\left(\mathrm{PHRR}_{\mathrm{BF}}\right)$, pyrolozate of species derived from the TDI component of the foam $\left(\mathrm{PHRR}_{1}\right)$, and pyrolyzate of species derived from the polyol component of the foam $\left(\mathrm{PHRR}_{2}\right)$. Four FPUF/BF did not follow this pattern, BFs 10, 16, 19, and 24. For BF-10, the barrier tended to split open and expose the underlying foam to direct heating. For BF-16 and BF-19, flame extinction was observed prior to fuel depletion. Reignition did not take place and there was no PHRR2. For BF-24, this material is not expected to be an effective barrier for flaming, and, as a result, no PHRR $R_{\mathrm{BF}}$ was identified.

Seven of the 16 FPUF/BF combinations tested in this study exhibited flame extinction prior to the polyol-derived material at the bottom of the test pan becoming involved. No additional burning would have been expected if the spark igniter had not been re-inserted and activated. These BFs either contained additives expected to release gas-phase FRs (BF-13, BF-15, and BF-16), had inherently fire-resistant fibers with low permeability BF structures (BF-9, BF-19 and BF-20), or had a FR backcoating that operates mainly in the condensed phase by forming a physical barrier between the fuel and the heat source (BF-23). These observations are consistent with active flame retardancy and barrier permeability being the dominant BF properties for flame extinction. Testing with three different burnt barriers indicated that these barriers were also effective in limiting heat transfer to the underlying substrate. The relative effectiveness of the remaining BFs in composites that did not show flame extinction seem to have been determined primarily by their ability to limit heating of the underlying FPUF and/or their physical integrity during testing.

Cone testing revealed distinct differences in qualitative composite burning behavior and quantitative HRR profiles based on the BF used. Three possible classification schemes based on flame extinction behavior, the peak heat release rate associated with burning of the liquid derived from polyol $\left(\mathrm{PHRR}_{2}\right)$ and PFIGRA 2 , which is $\mathrm{PHRR}_{2}$ normalized by the time it occurs, were introduced. Each contained three classes. The three classification approaches agreed with regard to particularly effective or ineffective barriers, each identifying BF-19 and BF-16 as Class 1 barriers and BF-24 as Class 3. Many variations between class assignments among the three schemes were found for BFs falling between these two extremes. The largest number occurred between the assignments based on the extinction behavior and the two approaches incorporating $\mathrm{PHRR}_{2}$. This is likely because the extinction and burning behaviors are dominated by different properties of the BFs. Variations in class assignments between the two approaches based on $\mathrm{PHRR}_{2}$ and PFIGRA 2 indicate that the timing of $\mathrm{PHRR}_{2}$ may be important in assessing BF performance in the cone tests. 
This study has demonstrated that while classification of BFs based cone calorimetry results is possible, a variety of schemes are possible. Since the ultimate goal is an approach to predict the effectiveness of BFs in real-scale RUF, additional work, including real-scale testing, is required to assess which, if any, of the three schemes will prove effective for this purpose. The availability of an approach for predicting BF effectiveness would prove invaluable for the design of RUF with improved fire performance.

While the current study has demonstrated that cone calorimeter experiments utilizing FPUF/BF composites can be utilized to develop classification schemes for BF effectiveness, it must be kept in mind that the results are likely to depend strongly on experimental conditions. Both the configuration, imposed heat flux, and operating conditions of the cone calorimeter as well as the sample configuration are expected to impact the results.

This study has demonstrated that heat losses from the aluminum sample pan, and thus the underlying substrate, have a strong effect on the burning behavior of the polyol-derived material that collects at the bottom. Flame extinction was identified as an important process and formed the basis for one the classification schemes. The experimental protocol called for the spark ignition source to be reinserted above the center of the sample and energized following flame extinction. Reignition of the flame requires at a minimum the presence of a combustible fuel mixture close to the spark source. A number of processes determine whether such a mixture forms including fuel pyrolysis rate, potential for mixing with air, and pyrolysis gas flow path. These processes depend, in turn, on composite configuration and BF properties. As an example, porous barriers allow released pyrolysis gases to flow directly to the spark location while an impervious barrier will force any released pyrolysis gases to flow out at the base of the barrier cage and escape upwards in the space between the BF sidewalls and the aluminum pan. The formation of a flammable mixture at the spark igniter would seem to be more difficult in the latter case. Composite burning behavior is also expected to be strongly affected by the level of applied heat flux from the cone heater. Here, the commonly recommended level of $35 \mathrm{~kW} / \mathrm{m}^{2}$ was used, but other levels need to be examined and considered. Changes in applied heat flux levels would likely result in changing BF classes within the three classification schemes.

As a final remark, it is emphasized once again that while this study has demonstrated that cone calorimeter testing provides the ability to distinguish between BF effectiveness for the particular composite sample configuration and experimental conditions utilized, it remains to be shown how the chosen classification schemes will correlate with BF performance and effectiveness in full-scaleup. 


\section{References}

[1] Ahrens M. Home Fires that Began with Upholstered Furniture, NFPA No. Put USS56, National Fire Protection Association, Quincy, MA, February 2017, 70 pp.

[2] Hall JR. Estimating fires when a product is the primary fuel but not the first fuel, with an application to upholstered furniture, Fire Technology 2015; 51 (2): 381-391.

[3] Palmer KN, Taylor W, and Paul KT. Fire Hazards of Plastics in Furniture and Furnishings: Characteristics of the Burning, BRE 3/75, Her Majesties Stationary Office, London, England, January 1975, 63 pp.

[4] Prager FH, Darr WC, and Wood JF. The contribution of upholstered furniture to residential fire risk, Cellular Polymers 1984; 3: 161-194.

[5] Nazaré S and Davis R. A review of fire blocking technologies for soft furnishings. Fire Science Reviews 2012;1:1

[6] Nazaré S, Pitts WM, Flynn S, Shields J, Davis RD. Evaluating fire blocking performance of barrier fabrics. Fire and Materials 2014; 38: 695-716.

[7] Nazaré S, Pitts WM, Matko S, Shields J, Davis RD. Evaluating smoldering behavior of barrier fabrics. Journal of Fire Sciences 2014; 32: 539-562.

[8] Nazaré S, Pitts WM, Shields J, Davis RD. Factors for consideration in an open-flame test for assessing fire blocking performance of barrier fabrics, Polymers, open access, 2016.

[9] Gallagher, JA. Interliner effect on the fire performance of upholstery materials. Journal of Fire Sciences 1993; 11: 87-105.

[10] Gallagher JA. Minimum flux for fire propagation: A new parameter for classification of foam/fabric composites. Journal of Fire Sciences 1992; 10: 40-57.

[11] Vanspeybroeck R, Hees PV, and Vandevelde P. Combustion behavior of Fabric and polyurethane flexible foam mock-up combinations under cone calorimetry test conditions. Fire and Materials 1993; 17:167-172.

[12] Petrella RV. The assessment of full-scale fire hazard from cone calorimeter data. Journal of Fire Sciences 1994; 12:14- 43.

[13] Babrauskas V. Bench-scale methods for prediction of full-scale behavior of furnishings and wall linings, SPFE Technical Report 84-10 (1984) Boston, MA.

[14] Babrauskas V, Baroudi D, Myllymaki J, and Kokkala M. The cone calorimeter used for predictions of the full-scale burning behavior of upholstered furniture. Fire and Materials 1997; 21: 95-105.

[15] Fire Safety of Upholstered Furniture- the final report on the CBUF research Programme. Edited by Bjorn Sundstorm, European Commission Measurement Testing Report EUR 16477 EN, 1995.

[16] Price D, Liu Y, Hull TR, Milnes GJ, Kandola BK, and Horrocks AR. Burning behavior of fabric/polyurethane foam combinations in the cone calorimeter. Polymer International 2000; 49:1153-1157.

[17] Kotresh TM, Indushekar R, Subbulakshmi MS, Vijayalaxmi SN, Krishna Prasad AS, Padaki VC and Agrawal AK. Effect of heat flux on the burning behavior of foam and foam/Nomex III fabric combination in the cone calorimeter. Polymer Testing 2006; 25:744-757.

[18] Coles AR. Flammability of Upholstered Furniture Using the Cone Calorimeter, Fire Engineering Report 2001/1, Canterbury University, Christchurch, New Zealand, (2001). 
[19] Janssens ML, Reducing Uncertainty of Quantifying the Burning Rate of Upholstered Furniture, Document Number 239050, U. S. Department of Justice, Washington, DC, 208 pp, (July 2012).

[20] Ostman BA-L, Nussbaum RM. Correlation between small scale rate of heat release and full scale room flashover for surface linings, in: Fire Safety Science- Proceedings of Second International Symposium, Hemisphere Publishing, New York, 823-832 (1989).

[21] Hirschler MM, Shakir S. Comparison of the fire performance of various upholstered furniture composite combinations (fabric/foam) in two rate of heat release calorimeters: Cone and Ohio State University instruments. Journal of Fire Sciences 1991; 9 (3): 223248.

[22] Hirschler MM, and. Smith GF. Flammability of sets of fabric/foam combinations for use in upholstered furniture, Fire Safety Journal 1990; 16:13-31.

[23] Babrauskas V, Wetterlund I. Testing of furniture composites in the cone calorimeter: A new specimen preparation method and round robin results, Fire Safety Journal 1998; 30(2): 179-194.

[24] Martini P. Development of low-cost fire blocking inter-liners for New Zealand furniture. Fire Engineering Research Report 08/5 2008 submitted in partial fulfilment of the requirements for the degree of Masters of Engineering in Fire Engineering, University of Canterbury, New Zealand.

[25] Forsten HH. Use of small scale testing to predict Cal 133 performance. Fire and Materials 1997; 21: 153- 160.

[26] Ohlemiller TJ and Shields JR. Behavior of mock-ups in the California Technical Bulletin 133 test protocol: Fabric and barrier effects. NISTIR 5653, 1995, National Institute of Standards and Technology, Gaithersburg, MD 20878.

[27] Zammarano M, Cazzetta V, Nazaré S, Shields JR, Kim YK, Hoffman KM, Maffezzoli A, and Davis R. Smoldering and flame resistant textiles via conformal barrier formation. Advanced Material Interfaces 2016; 23. https://doi.org/10.1002/admi.201600617

[28] Storesund K, Steen-Hansen A, and Bergstrand A. Fire Sate Upholstered Furniture: Alternative strategies to the use of chemical flame retardants. SP Fire Research Report A15 20124:2. Available from: http://en.spfr.no/media/publikasjoner/upload/2015/rapport-spfr-a15-20124-2.pdf

[29] Fabian T. Upholstered Furniture Flammability, Research Report, Underwriters Laboratory Inc., (July 31st 2013).

[30] Nazaré S, Pitts WM, Shields J. Fire-blocking performance of laminated barrier fabrics: Cone calorimetric characterization, in Fire and Materials Conference Proceedings, San Francisco, CA, February 2017.

[31] Schartel B, Wilkie CA, Camino G. Recommendation on the scientific approach to polymer flame retardancy: Part I_ Scientific terms and methods. Journal of Fire Sciences 2016; 34(6): 447-467.

[32] Morice L, Bourbigot S, Leroy J-M. Heat transfer study of polypropylene-based intumescent systems during combustion. Journal of Fire Science 1997; 15:358-374.

[33] Bartholmai M, Schriever R, Schartel B. Influence of external heat flux and coating thickness on the thermal insulation properties of two different intumescent coating using cone calorimeter and numerical analysis. Fire and Materials 2003; 27:151-162. 
[34] Duquesne S, Magnet S, Jama C, Delobel R. Thermoplastic resins for thin intumescent coatings - towards a better understanding of their effect on intumescence efficiency. Polymer Degradation and Stability 2005; 88:63-69.

[35] Bartholmai M, Schartel B. Assessing the performance of intumescent coatings using bench-scaled cone calorimeter and finite difference simulations. Fire and Materials 2007; 31:187-205.

[36] Schartel B and Weiß A. Temperature inside polymer specimen: pyrolysis zone and shielding. Fire and Materials 2010; 34: 217-235.

[37] Putzeys O, Bar-Ilan A, Rein G, Fernandez-Pello AC, Urban DL. The role of secondary char oxidation in the transition from smoldering to flaming. Proceedings of the Combustion Institute 2007; 31: 2669-2676.

[38] Putzeys OM, Fernandez-Pello AC, Rein G, Urban DL. The piloted transition to flaming in smoldering fire retarded and non-fire retarded polyurethane foam. Fire and Materials 2008; 32: 485-499.

[39] Hadden R, Alkatib A, Rein G, Torero JL. Radiant ignition of polyurethane foam: The effect of sample size. Fire Technology 2014; 50: 673-691.

[40] Weil ED and Levchik SV. Flame retardants in commercial use or development for textiles. 2008; 26: 243-281.

[41] Memoranda to Andrew Lock, Project Manager, Full-Scale Upholstered Furniture Testing, 2014-2015, from Linda Fansler, Division of engineering, January 2016.

[42] State of California Department of Consumer Affairs. Technical Bulletin Cal-1172013: Proposed Open Flame Test for Barrier Materials. Bureau of Electronic and Appliance Repair Home Furnishings and Thermal Insulation, 4244 South Market Court, Suite D, Sacramento, CA 95834-1243.

[43] Zammarano M., Matko S., Kramer RH., Davis RD., Gilman JW., Sung LP., Fox DM., and Mehta S. Smoldering in flexible polyurethane foams: The effect of foam morphology. Chapter 29 in Fire and Polymers VI: New Advances in Flame Retardant Chemistry and Science; Morgan A (Ed). ACS Symposium Series; Washington DC 2012.

[44] Babrauskas V. Development of the Cone Calorimeter A Bench-Scale Heat Release Rate Apparatus Based on Oxygen Consumption (NBSIR 82-2611). [U.S.] Natl. Bur. Stand. (1982).

[45] Thornton W. The relation of oxygen to the heat of combustion of organic compounds. Philosophical Magazine and Journal of Science 1917; 33:196-203.

[46] Bryant RA, Ohlemiller TJ, Johnsson EL, Hamins A, Grove BS, Guthrie WF, Maranghides A, and Mulholland GW. The NIST 3 Megawatt Quantitative Heat Release Rate Facility, NIST Special Publication 1007, National Institute of Standards and Technology, Gaithersburg, MD, December 2003, 81 pp.

[47] Enright P and Fleishmann C. Uncertainty of heat release rate calculation of the ISO 5660- 1 Cone Standard Test Method. Fire Technology 1998; 35 (2): 152-169.

[48] Lukošius A and Vekteris V. Precision of heat release rate measurement results. Measurement Science Review 2003; 3 (3): 13-16

[49] ASTM E 1474: Standard Test Method for Determining the Heat Release Rate of Upholstered Furniture and Mattress Components or Composites Using a Bench Scale Oxygen Consumption Calorimeter. 
[50] Messerschmidt B, Hees P. Influence of delay times and response times on heat release measurements. Fire and Materials 2000; 24: 121-130.

[51] Lyon RE, Abramowitz A. Effect of instrument response time on heat release measurements. Fire and Materials 1995; 19:11-17.

[52] Pitts WM. Applied heat flux distribution and time response effects on cone calorimeter characterization of a commercial flexible foam. Fire Technology 2014; 50: 635-672. DOI: 10.1007/s10694-011-0235-8.

[53] Sundstorm B. Estimating fire hazard due to the burning behavior of upholstered furniture. In proceeding of The Second International Conference on the Testing of Polymers, 5th-6th September 1996, Rapra Technology Limited, Shawbury, Shrewsbury, Shropshire SY4 4NR, UK.

[54] EN 13501:2002. Fire Classification of Construction Products and Building Elements-Part 1: Classification Using Test Data from Reaction to Fire Tests. European Committee for Standardization (CEN), Brussels, Inc.: Belgium, 2002.

[55] Pitts WM, Braun E, Peacock, RD, Mitler HE, Johnsson, EL, Reneke PA, and Blevins LG. Temperature Uncertainties for Bare-Bead and Aspirated Thermocouple Measurements in Fire Environments, Thermal measurements: The Foundation of Fire Standards, ASTM, STP 1427 L.A Gritzo and N.J Alvares, Eds., ASTM International, West Conshohocken, PA, 2002.

[56] Valancia LB, Rogaume T, Guillaume E, Rein G, and Torero JL. Analysis of principal gas products during combustion of polyether polyurethane foam at different irradiance levels, Fire Safety Journal 2009; 44: 933-940.

[57] Ravey M, Pearce EM. Flexible polyurethane foam. I. Thermal decomposition of a polyether-based, water-blown commercial type of flexible polyurethane foam. Journal of Applied Polymer Science 1997; 63 (1): 47-74.

[58] Kramer RH, Zammarano M, Linteris GT, Gedde UW, Gilman JW. Heat release and structural collapse of flexible polyurethane foam. Polymer Degradation Stability 2010; 95:1115-1122.

[59] Pitts WM. Role of two stage pyrolysis in fire growth on flexible polyurethane foam slabs. Fire and Materials 2014; 38: 323-338.

[60] Robson LD, Trovi DA, Obach MR, and Weckman EJ. Effects of variations in incident heat flux when using cone calorimeter test data for prediction of full-scale heat release rates of polyurethane foam. Fire and Materials 2016; 40: 89-113.

[61] Schartel B, Bartholmai M, Knoll U. Some comments on the use of cone calorimeter data. Polymer Degradation and Stability 2005; 88: 540-547.

[62] Babrauskas V and Peacock RD. Heat Release Rate - The single most important variable in fire hazard. Fire Safety Journal 1992; 18 (3):255-272.

[63] Blum A and Ames BN, Flame-Retartant Additives as Possible Cancer Hazards, Science 1977; 195 (4273): 17-23.

[64] Letcher R and Behnisch P, Eds., The State-of-Science and Trends of BFRs in the Environment, Environment International 2003; 29 (6): 663-886. 